\title{
Walls and Strategic Innovation in Violent Conflict
}

\author{
Matthew Nanes \\ Trevor Bachus \\ Saint Louis University* \\ Saint Louis University ${ }^{\dagger}$
}

May 21, 2020

\begin{abstract}
Governments build walls to curtail a range of illicit activities like immigration, crime, and terrorism. What impact do walls have on the characteristics of illicit activity? We argue that while physical barriers can effectively prevent a narrow category of unwanted behavior, they induce actors to respond strategically and develop new tactics, changing the nature of illicit activity and leading to new threats. We test this argument in the context of Israel's security barrier built to reduce terror attacks. Using an instrumental variable unrelated to the underlying threat of attack, we analyze short-term changes in the barrier's porousness. We find that terror attacks in Israel are indeed less likely when the barrier is more secure. However, we also observe evidence of displacement. Attacks and fatalities are most likely immediately after the government eases temporary restrictions on movement, suggesting that previously-planned attacks were delayed, not prevented. Furthermore, when the barrier is more secure, terrorists substitute weapons that are less affected by the barrier, and carry out attacks in systematically different locations. Ultimately, walls' impacts on any challenge depend not just on how well they prevent movement but also on illicit actors' strategic responses.
\end{abstract}

Governments worldwide use walls and other physical barriers to limit undesired movement of people and goods, including illegal immigration (Hassner and Wittenberg 2015; Carter and Poast 2017), crime (Getmansky et al. 2019; Laughlin 2019), and terrorism (Thein 2004; Abrahams 2019). Despite their prevalence, we know little about these barriers' impacts. Beyond the simple question of how well they prevent a specific type of movement across a specific location, barriers may change the nature of illicit activity by shifting its location or tactics. Criminals may find unguarded sections of borders to use for smuggling

*Assistant Professor, Political Science. matthew.nanes@slu.edu.

${ }^{\dagger}$ MA Candidate, Political Science. trevor.bachus@slu.edu. The authors thank Alexei Abrahams, Dotan Haim, Steven Rogers, Zachary Steinert-Threlkeld, and audiences at the University of Florida Research Seminar in Politics and the MPSA 2019 meeting for their comments. 
(Getmansky et al. 2019; Laughlin 2019), and illegal immigrants may cross a border via ports of entry using forged documents if walls block other paths. To what extent do barriers incentivize illicit actors to innovate or change their strategy, and how do these changes affect the nature of the underlying political problem?

We study the use of physical barriers to prevent terrorist violence, an outcome which should be particularly susceptible to spillovers and strategic innovation in response to wallbuilding. Terrorists' success is not tied to accessing a specific target with a specific weapon. When government policies prevent access to preferred targets, terrorists' can shift their attention to a near-infinite selection of viable alternatives, or to a tactic which is not stymied by a physical barrier (Enders and Sandler 1993; Powell 2007). Tilly (1993) notes that participants in insurrection select new tactics from "repertoires of contention" in response to changing conditions. Barriers which stymie existing tactics alter terrorists' cost structures without changing their goals. Terrorists should therefore find new ways to achieve their goals that are unaffected by physical defenses.

We test these arguments in the context of the "separation barrier" built by the Israeli government in the early 2000s to prevent terrorists in the West Bank from accessing targets in Israel Proper. ${ }^{1}$ We operationalize variation in the barrier's porousness using the closures of checkpoints which regulate movement between the two sides. ${ }^{2}$ On most days, checkpoints allow controlled access across the barrier, providing opportunities for terrorists to sneak through. Periodic closures generate temporarily reduce porousness, providing a counterfactual to the barrier's presence which allow us to evaluate its impact. Given that the timing of closures is endogenous to the underlying threat of attack, we employ an instrumental variable, Israeli holidays, which strongly predicts checkpoint closures but is correlated with

\footnotetext{
${ }^{1}$ We label territory governed by civilian (rather than military) law as "Israel Proper," which includes territory part of Israel's 1948 boarders as well as annexed portions of greater Jerusalem and the Golan Heights.

${ }^{2}$ As we describe below, a minority of the 440 mile barrier is a wall. The rest consists of fences and remote sensors. Most "walls" in the studies we cite are actually a combination of walls, fences, and other obstacles designed to prevent movement. The relevant characteristic is not a barrier's construction material, but the government's use of physical obstacles to prevent undesired movement.
} 
the threat of attack almost exclusively through changes in the barrier's porousness.

Drawing on new data on the date, location, and weapon of every terrorist attack in Israel and the Palestinian Territories between 2000 and 2017, we find that checkpoint closures reduce the likelihood of at least one terror attack occurring on a date by about 8.5 percentage points. However, we find no link between the barrier's porousness and the number of terror fatalities on a particular day. Furthermore, there is some indication that sealing the barrier delays rather than reduces attacks: when checkpoints are open, the highest probability of attack comes immediately following a closure. These mixed impacts of the barrier are exacerbated by apparent terrorist substitution of tactics and targets. Among attacks that occur, a higher proportion use weapons of convenience like knives, cars, and Molotov cocktails when the barrier is sealed, presumably because these weapons are readily available on both sides. A higher proportion of attacks also use suicide bombings when the barrier is sealed. Finally, attacks in Israel Proper occur significantly closer to the security barrier on days when checkpoints are closed, indicating a systematic shift in target selection.

This study tests existing theories from both the academic literature (Enders and Sandler 1993; Berman and Laitin 2005; Powell 2007) and supposed best practices in the security community (Newman and Clarke 2008) using fine-grained data with a clear identification strategy to isolate hypothesized effects from global trends. We also build on existing theories of terrorist substitution by developing and testing new hypotheses on the timing of attacks given the temporary nature of many counterterrorism policies. Because counterterrorism tools inconvenience legitimate as well as illicit actors, governments tend to vary their intensity over time, ramping up implementation only when expedient. Knowing that border closures, bans of electronics in air passengers' carry-on luggage, and searches of event attendees are unlikely to continue indefinitely, terrorists may elect to delay their attacks. Thus, a reduction in violence when a particular policy is in use does not necessarily indicate that the policy reduced overall levels of violence.

Finally, our findings contribute to a broader understanding of walls and barriers. More 
than 60 border walls exist world-wide, nearly half of which have been built since 2000 (Carter and Poast 2017). Yet, because of the endogenous nature of their construction, existing work provides little evidence on their effects. We identify ways that strategic responses to wall construction change the nature of conflict and provide much-needed evidence on the impacts of a highly contentious barrier.

\section{Walls, Barriers, and Politics}

Governments frequently use barriers to control the movement of people and goods, especially across national borders. Carter and Poast (2017) count 62 unique border walls between 1800 and 2014. These projects are both increasingly prominent and poorly understood. A number of studies explore when and why states construct walls and barriers, finding that the majority of border walls are built by wealthy states attempting to keep out unwanted migrants (Hassner and Wittenberg 2015; Carter and Poast 2017). Other walls separate criminals from potential victims and insurgents from likely targets (Spencer 2016).

Despite the rapidly increasing number of walls world-wide, few studies empirically evaluate their effects. Those that do find that barriers displace behavior, creating negative externalities for unprotected areas. Laughlin (2019) finds that sections of barriers built along the US-Mexico border in 2007 disrupted existing smuggling routes, causing cartels to violently compete for access to un-walled stretches of border. Vehicle thefts in Israel (Getmansky et al. 2019), drug violence in Venezuela (Kronick 2019), and property crime in Colombia (Blattman et al. 2017) shift noticeably from one location to another following changes in physical security. Thus, a full analysis of walls' impacts must evaluate not just whether they prevent particular access to a specific location, but also their broader effects on surrounding areas and the ways in which illicit actors' tactical responses shape the nature of conflict.

Governments often use walls to prevent terrorism. In December 2019, US President Donald Trump claimed that a border wall between the US and Mexico is imperative because 
"we have terrorists coming in through the southern border." 3 Just a few weeks later, US Secretary of State Mike Pompeo similarly stated that failure to complete the border wall "includes the risk that we have terrorists come across that border." 4 The governments of India (along its border with Pakistan), Saudi Arabia (along its border with Yemen), Turkey (along its border with Syria), Morocco (in disputed Western Sahara), and the United Kingdom (in Belfast) have all constructed walls aimed at reducing terrorist or insurgent violence by separating attackers from targets (Thein 2004).

Israel's "security barrier" presents perhaps the best-known use of a large barrier for counterterrorism. In the early 2000s, the Israeli government began building fences and concrete walls to separate Palestinian Authority-controlled sections of the West Bank from Israel Proper. The Israeli Ministry of Foreign Affairs explains that the barrier is necessary because "more than 1,100 people have been murdered in attacks carried out by Palestinian terrorists since September 2000...In almost all of the cases, the terrorists came from Palestinian areas in the West Bank. The absence of a barrier there had made infiltration into Israel communities a relatively easy task for terrorists." 5

This use of walls as counterterrorism is not surprising given the political incentives governments face to signal competence in security provision. Existing research notes that incumbent governments have an incentive to over-provide visible counterterrorism beyond the amount necessary to prevent attacks (Bueno de Mesquita 2007; Nanes 2017; Harish and Little 2017; Aksoy 2018). In the absence of terror attacks, citizens do not know whether to attribute security to effective government action or a lack of effort by terrorists. Thus, governments provide visible counterterrorism like walls, airport security screening, barricades around federal buildings, and security cameras not just when those measures prevent attacks efficiently but also to demonstrate action and claim credit for positive security outcomes.

\footnotetext{
${ }^{3}$ Blake, Aaron, "The GOP's pernicious link between terrorism and the border wall." The Washington Post 4 January 2019, https://www.washingtonpost.com/politics/2019/01/04/ gops-pernicious-link-between-terrorism-border-wall/

${ }^{4}$ ibid

${ }^{5}$ https://mfa.gov.il/mfa/foreignpolicy/faq/pages/israel- $\% 20$ the $\% 20$ conflict $\% 20$ and $\%$ 20 peace- $\% 20$ answers $\% 20$ to\%20frequen. aspx\#fence
} 


\section{Strategic Innovation in Terrorist Violence}

Terrorists deciding when, where, and how to commit violence consider the likely costs and benefits of the attack. Benefits depend largely on how well violence achieves terrorists' underlying political goals. Costs include the likelihood of being captured or killed, as well as financial and material costs of attack. Walls aim to prevent terrorism by raising the costs of an attack, forcing terrorists to travel farther and therefore increasing the likelihood of being identified. They may also interrupt terrorists' supply chains, making weapons more difficult to procure. Thus, there is good reason to think that walls should "work" in a narrow sense, leading to fewer attacks.

Hypothesis 1: Walls and barriers separating terrorists from their preferred targets will reduce the frequency of terror attacks.

Though walls affect the costs of terrorism, they do not address terrorists' underlying motives for violence. Terrorists should respond strategically to walls by selecting new tactics, targets, or times to attack that minimize their costs and still allow them to pursue their broader political goals by perpetrating violence. This strategic innovation is aided by the characteristics of walls and terrorism. Walls are unwieldy, immobile, and require considerable time to build. They are costly for governments not just because of the price of construction, which can account for hundreds of millions of dollars, but also because they disrupt daily life by preventing desirable as well as undesirable movement. Tens of thousands of Israeli citizens and Palestinians cross legitimately between the West Bank and Israel Proper every day to work, shop, and conduct business. Terrorism, on the other hand, need not occur at a specific time or in a particular place (Crenshaw 1981), so terrorists may innovate and develop strategies which are not stymied by walls. Just as businesses innovate in the face of changing market conditions or cost structures, terrorists facing physical barriers should find other ways to achieve their goals that are unaffected by those defenses. 
Terrorists' strategic innovation may occur on a number of dimensions. Physical security often varies in intensity over time, incentivizing would-be attackers to wait until restrictions are lifted before implementing their plots. The familiar refrain of "heightened terror threat levels," which often comes with additional security restrictions, implies a temporary situation. As we describe below, the Israeli government periodically declares "comprehensive closures" during which all movement across the barrier stops. Particularly in a long-running conflict like the one in Israel, the underlying political motives that drive individuals to commit terrorism are unlikely to vary substantially from day to day. Thus, variation in realized terror must result from variation in opportunity. Terrorists may simply wait until the government reduces physical security before proceeding with their plans.

Hypothesis 2: The probability of a terror attack will be highest immediately following the removal of physical security.

Terrorists' innovation on another dimension, weapons and tactics, can permanently change the nature of violent conflict. Tilly (1993) writes that people posses "repertoires" of tactics for collective resistance against the government, and that the methods they select change depending on the nature of the conflict. "People learn to break windows in protest, attack pilloried prisoners, tear down dishonored houses, stage public marches, petition, hold formal meetings, organize special-interest associations. At any particular point in history, however, they learn only a rather small number of alternative ways to act collectively" (264).

Terrorists who observe a substantial investment by their opponent in unwieldy physical security may develop weapons and tactics which are unaffected by that security. In response to airport metal detectors, al-Qaeda hatched a plot to smuggle liquid explosives onto airplanes. ${ }^{6}$ Measures which limit access may induce terrorists to use weapons which do not require them to personally access their target. Concrete barricades block vehicle-born

\footnotetext{
6 "Agent infiltrated terror cell, U.S. says." CNN, 11 August 2006. http://www.cnn.com/2006/US/08/ 10/us. security/index.html.
} 
devices but cannot stop biological weapons like anthrax powder from being delivered by mail. Fences prevent human access, but they do not stop rockets or mortars from being launched overhead. This innovation comes not just in the form of substituting existing tactics (Enders and Sandler 1993), but also the development of entirely new methods of violence that neither terrorists nor governments had previously considered.

Hypothesis 3: Terrorists will turn to methods of violence that are less affected by walls when walls prevent previous tactics from succeeding.

Finally, terrorism uses violence to induce fear, a goal which can be achieved by attacking a nearly infinite set of targets (Crenshaw 1981; Hoffman 2003). At the same time, physical security is too costly to employ with $100 \%$ coverage. Even in a small country like Israel with substantial population sorting, it is not feasible to build a wall separating all potential attackers from all potential targets. The same limitation is true of other forms of physical security. The US places body scanners and x-ray machines at airport terminals, but insisting on similarly restrictive measures at every shopping mall and sports arena is not feasible. The nature of terrorism provides a menu of viable targets which is simply too large to protect using physical security (Powell 2007).

Hypothesis 4: Walls will cause a shift in terrorism away from protected targets towards unprotected targets.

The likelihood of terrorist innovation makes the question of whether walls "work" difficult to answer. On the one hand, it seems likely that walls reduce the types of attacks which they were constructed to prevent, though rigorous evidence of even this limited impact remains in short supply. Whether they should reduce overall levels of violence or move the parties closer to a peaceful resolution is less clear. If walls force terrorists to use less lethal 
tactics against less impactful targets, then they may force terrorists to reduce their demands and return to the bargaining table. On the other hand, in the absence of corresponding measures which address terrorists' underlying motives for violence, terrorists' strategic innovation in response to wall-building may perpetuate conflict by rewarding opponents that are nimble and adaptable.

\section{Empirical Context: The Israeli-Palestinian Conflict}

We study the effects of a counterterrorism barrier on violent conflict in Israel. Terrorism in Israel is highly relevant globally, both for Israel's strategic importance and for the frequency and intensity of violence. Given the Israeli military's vast superiority in conventional warfare, some individuals and groups seeking to establish a Palestinian state on Israeli-controlled land turn to terrorism. From September 2000 through September 2017, Palestinians killed 813 Israeli civilians, including 522 in Israel Proper. ${ }^{7}$

Israel is also a good case for analysis because we can access unusually granular data on counterterrorism strategies, including barriers built to prevent would-be attackers originating in the West Bank and Gaza from accessing the rest of Israel. Israel first constructed a barrier around Gaza in the mid-1990s. Between 2000 and 2018, it built more than 700 kilometers of fences, concrete walls, and ditches between the West Bank and Israel Proper. Movement within the West Bank is further restricted by walls and checkpoints which isolate noncitizen Palestinians from Israelis (Longo et al. 2014; Abrahams 2019). The construction of the West Bank security barrier varies. In urban areas, 25-foot tall concrete slabs aim not just to impede human traffic but also to block sniper fire. In rural areas, the barrier is a combination of fences, automated sensors, trenches, and patrol roads (Hassner and Wittenberg 2015). Although only a small portion of the barrier is technically a wall, the entire structure significantly raises the costs of crossing between the West Bank and Israel Proper. This variance in physical construction is present in other so-called walls, including

\footnotetext{
7 "Targeting of Israeli Civilians by Palestinians." B'Tselem.org, 11 November 2017. https://www. btselem.org/israeli_civilians.
} 
along US-Mexico border. Ultimately, governments will use the style of barrier that they expect to effectively curtail movement at the lowest cost. Chain link fences, remote sensors, and concrete walls are all part of the same tactical attempt to restrict movement and can be evaluated similarly.

Individuals from both the West Bank and Israel Proper have carried out terror attacks on both sides of the security barrier. However, a majority of attackers originate on the West Bank side. Of the 513 attacks in which we were able to identify the attacker's home town, only $7.8 \%$ came from Israel Proper. The challenge for terrorist organizations based in the West Bank is to connect weapons and individuals with targets, the most appealing of which lie on the Israel Proper side of the security barrier. The government allows crossings between the two areas at a series of checkpoints. On most days, about 70,000 Palestinians travel across the barrier to work for Israeli companies and spend money in Israeli shops. ${ }^{8}$

If the security barrier makes it more difficult for terrorists to access their preferred targets, why allow crossings at all? The Israeli economy relies on Palestinians who live on one side of the barrier and work on the other, and on goods produced in Israel that are sold to Palestinians in the West Bank. Closures also elicit international criticism on human rights grounds, including from allies upon whose support Israel relies. Thus, Israel incurs costs from closures and does not use them without cause. Excluding the Second Intifada, during which high levels of conflict mandated long closures of the barrier, closures typically last only a few days, and never more than a few weeks.

We follow a long line of social science research in testing general theories of terrorism with evidence from the Israeli-Palestinian conflict due to its global relevance and access to high-quality data (Berman and Laitin 2005; Jaeger and Paserman 2008; Getmansky and Zeitzoff 2014). Yet, our theoretical argument on the effects of walls generalizes beyond this single case. Terrorists' strategic incentives to adapt to changing conditions applies regardless of whether their opponent is a democracy or an autocracy, or they operate in Asia, America,

\footnotetext{
${ }^{8}$ Activestills (2008), "Checkpoints," al-Jazeera English. https://interactive.aljazeera.com/aje/ 2018/commuting-through-israeli-checkpoints/index.html.
} 
or Europe. The dynamics we identify in this paper should hold true for countries as diverse as the United States, the Philippines, France, and Sri Lanka as they search for durable solutions to terrorism.

\section{Data and Empirical Strategy}

Walls are notoriously difficult to evaluate. First, the timing and location of their construction is endogenous to the underlying threat they set out to resolve. Second, once built they do not vary. Most evidence of walls' effectiveness presents a simple before and after comparison. For example, Israel's ministry of defense claims that the security barrier reduced suicide terrorism by $90 \%$ by comparing the number of attacks in 2002 to the number of attacks in 2012. Yet, this bivariate time series analysis fails to account for changes in the political environment, other security policies, shifts in available technology, and a plethora of other factors that change over time and are likely correlated with terrorism. ${ }^{9}$

We begin to solve this problem by exploiting variation in the porousness of Israel's security barrier that occurs when the government closes checkpoints. On about 1/4 of days, the government declares a "comprehensive closure" during which no movement is allowed across the barrier. Closure days occur primarily when tensions are highest. During the Second Intifada, the government closed checkpoints on $46.9 \%$ of days, compared to $9.8 \%$ of other days between January 2000 and December 2017. Slipping through a checkpoint through which some movement is allowed is easier than crossing a complex physical barrier across which all movement is illicit. Terrorists and criminals frequently use ambulances ${ }^{10}$ or Israelilicensed vehicles ${ }^{11}$ to transport people and weapons through checkpoints (Getmansky et al. 2019). Closing checkpoints makes these illegal crossings much more difficult. That terrorists

\footnotetext{
${ }^{9}$ Hauer, Sarah, "Scott Walker: Israel says its wall led to 90 percent reduction in terrorist attacks." Politifact 2 October 2015, https://www.politifact.com/factchecks/2015/oct/02/scott-walker/ scott-walker-israel-says-its-wall-led-90-percent-r/

${ }^{10}$ Reuters, "Israeli medics slam Palestinian bomb smuggling." ReliefWeb. 1 April 2002. https: //reliefweb.int/report/israel/israeli-medics-slam-palestinian-bomb-smuggling

${ }^{11}$ Gross, Judah Ari, "Israeli woman nabbed smuggling Palestinian man out of West Bank." Times of Israel 8 April 2019. https://www.timesofisrael.com/ israeli-woman-nabbed-smuggling-palestinian-man-out-of-west-bank/
} 
risk crossing through manned checkpoints indicates that they believe the checkpoints are more porous than the barrier itself. Similarly, the government's closure of checkpoints during periods of tension suggests that the government believes the risk of illicit travel through checkpoints is non-trivial.

Thus, checkpoint closures provide useful variation in the porousness of the security barrier, or the counterfactual whose absence Hassner and Wittenberg (2015) note usually prevents evaluations of walls' effectiveness. We use checkpoint closures to operationalize changes in the barrier's intensity, assuming that the 'treatment' of the barrier is weaker on days when traffic flows through the checkpoints than days when no movement is allowed. Israeli human rights organization B'Tselem acquired daily information on closures from the government through a freedom of information request and shared the data with us for this research.

The key dependent variables are the date, location, and weapon type for every terrorist attack carried out in Israel between January 1st, 2000 and December 31st, 2017. ${ }^{2}$ We conduct analyses at two levels, location-day and attack. Location-day addresses the wall's short-term impacts on violence, as we propose that the barrier pressures terrorist groups to conduct fewer attacks. Analyzing the attacks themselves speaks to the nature of the attacks, but not their likelihood. We focus on the number and nature of attacks rather than fatalities because an attack's lethality is influenced by a range of other factors, including slight variations in foot or vehicle traffic at the attack site, security's response at the attack site, the attacker's skill with his weapon, and unknown underlying health conditions of those in proximity to the attack, which have nothing to do with the barrier's influence. Instead, we believe the number and type of attacks is a much clearer indicator of terrorists' responses to the barrier. With these caveats, we draw a few cautious conclusions from analyses using fatalities as the dependent variable as well.

We conducted a comprehensive search of the Global Terrorism Database (GTD)

\footnotetext{
${ }^{12}$ The time period is determined by data availability for checkpoint closures.
} 
(START 2018), the Chicago Project on Security and Terrorism Suicide Attack Database (CPOST 2018), and the Jerusalem Post online archives, using additional online news sources to fill in details about events mentioned in these sources as needed. We include in our dataset any event in which violence was intentionally perpetrated in Israel or the Palestinian Territories with the intent of advancing a political goal. The appendix provides further information on our coding and inclusion criteria, as well as potential implications of our reliance on news sources. In total, we identified 2,719 terrorist attacks, including 1,579 in which the attacker physically accessed the target and 1,140 volleys of rockets or mortars. ${ }^{13}$ Figure 1 shows the number and nature of attacks per year.

Figure 1: Terrorism 2000-2017

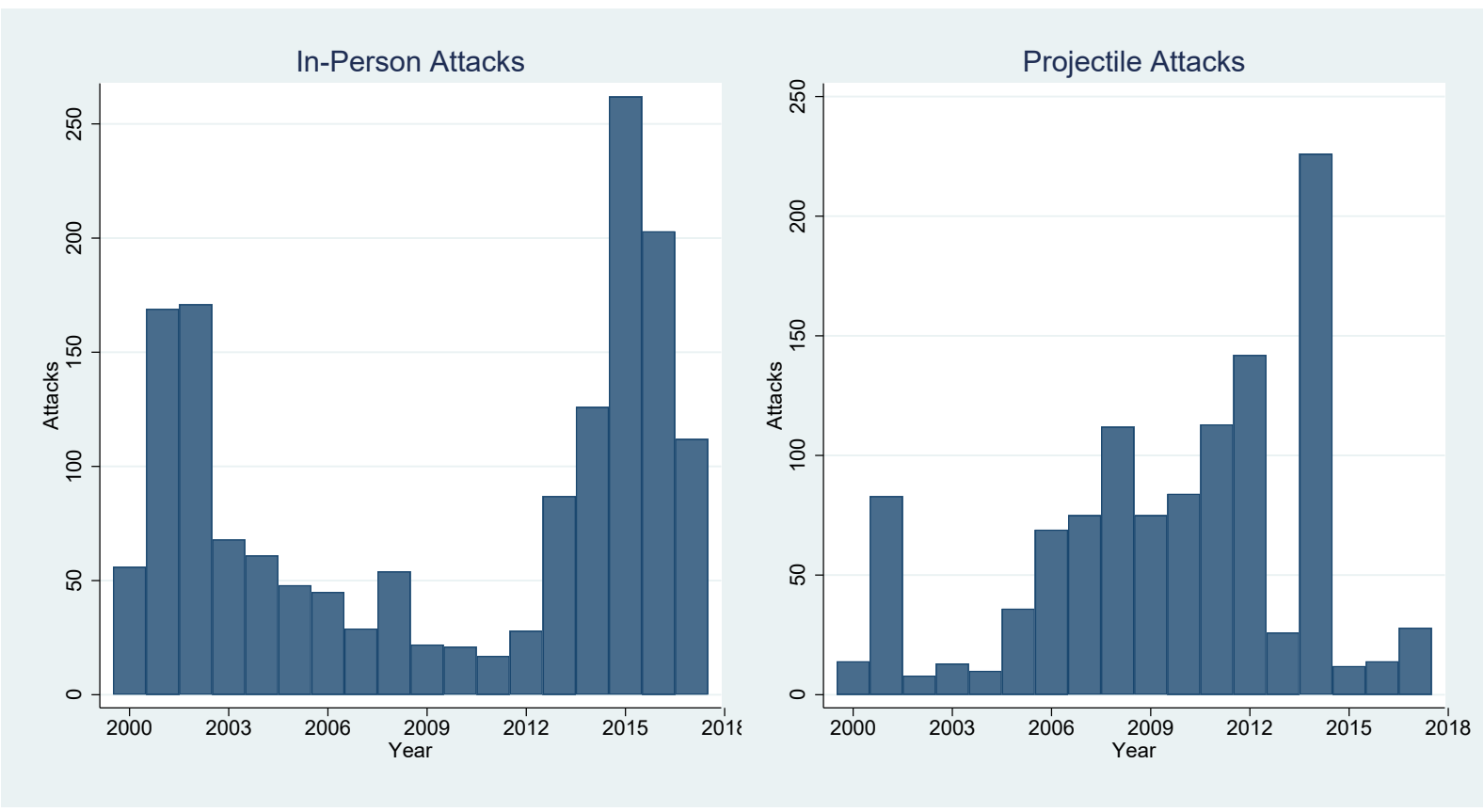

We further categorize non-projectile attacks into six groups: stabbings (27.3\%), shootings $(24.2 \%)$, non-suicide bombings (16.9\%), suicide bombings (15.4\%), firebombings or arson $(11.2 \%)$, and vehicle rammings (5.0\%). We were able to locate $67.1 \%$ of attacks within 1,000 meters (most to an exact location), and an additional 15.8\% within 2,000 meters. The remaining $17.1 \%$ were attributed to the nearest city. Location data was more precise in Israel

\footnotetext{
${ }^{13}$ Many of these attacks were comprised of dozens of individual rockets or mortars. We code each discrete volley as an attack, regardless of the number of projectiles fired.
} 
Proper, where only $11.8 \%$ of attacks are coded with worse than 2,000 meters of certainty. Figure 2 shows the location of all non-projectile attacks, with different colors representing different types of weapons. 
Figure 2: Terror Attack Locations and Weapons

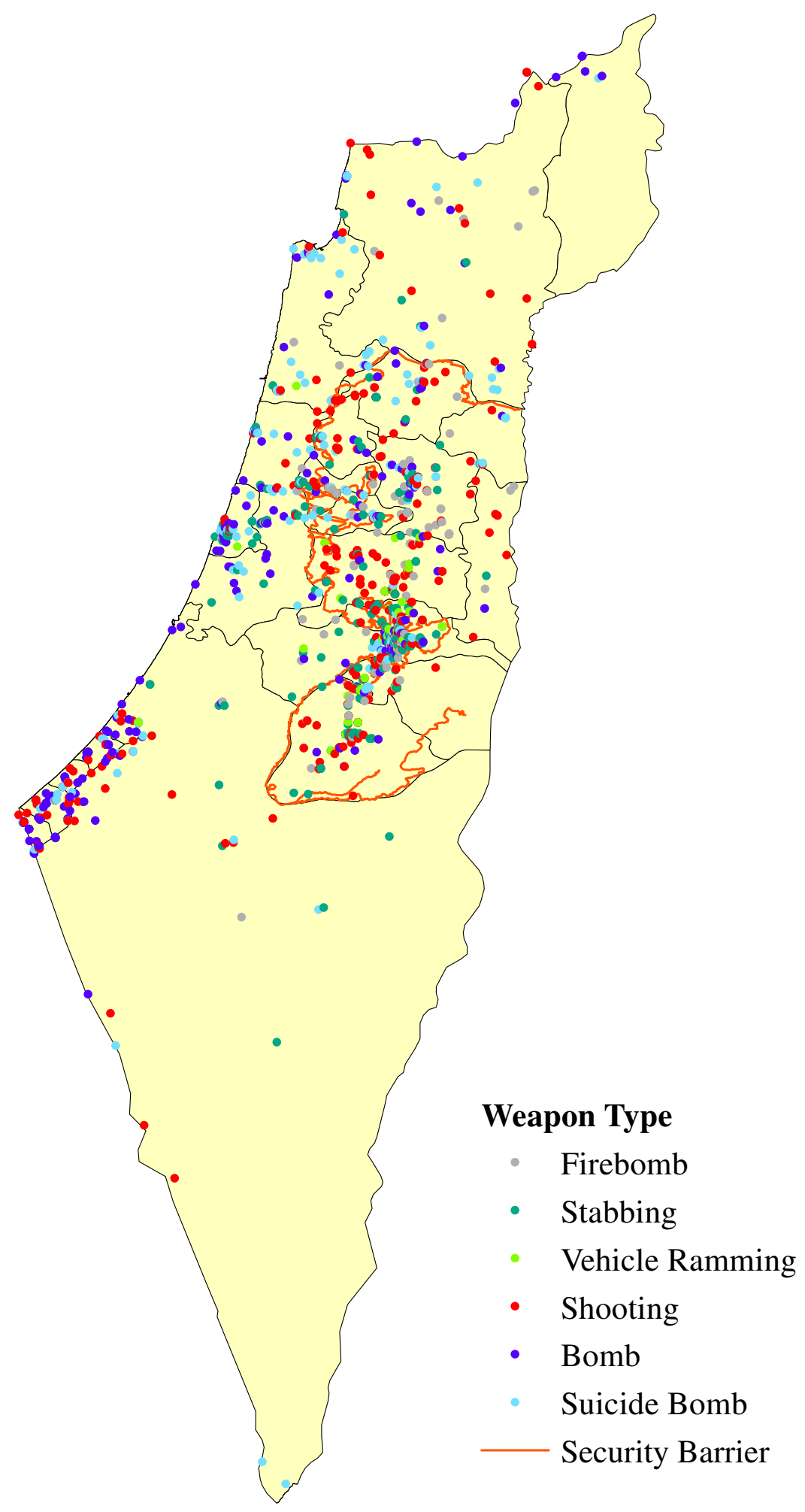




\section{Analysis and Results}

The strategic nature of counterterrorism poses a challenge for identifying the causal effect of closures on terrorism. The Israeli government closes checkpoints when it believes the threat of attack is higher, obscuring the independent effect of closures (i.e. variation in the barrier's porousness) on the likelihood of attacks. To address this problem, we test the impact of checkpoint closures for a reason other than the heightened threat of attacks: staffing limitations. The government frequently closes checkpoints on religious and secular holidays to allow soldiers to celebrate with their families. ${ }^{14}$ Since these closures are determined orthogonally to the underlying probability of attack, we employ holidays as an instrumental variable in a two-stage least squares (2SLS) regression. We use a day's designation as a holiday to predict whether checkpoints will be closed, and use that prediction as the key independent variable in a second-stage regression testing the link between closures and the likelihood of attacks. In the first stage, we control for the number of days until the next election, the partisanship of the government's security cabinet, and their interaction, which Nanes (2017) finds significantly predict the likelihood of a closure. In the Appendix, we show that the main results are robust to removing these controls.

Holidays are a strong instrument for closures: checkpoints were closed on $61.7 \%$ of holidays, compared to $15.3 \%$ of non-holidays. ${ }^{15}$ The first-stage model predicts nearly $30 \%$ of the variation in checkpoint closures with an F statistic above 200 (see Appendix).

We argue that in this context, holidays also meet the exclusion restriction, or the requirement that they impact terrorism only through their influence on checkpoint closures, to a sufficient extent that this approach improves substantially on a naive regression analysis. Many of the links between holidays and terrorism discussed in existing research do not apply

\footnotetext{
${ }^{14}$ Documents obtained by human rights group B'Tselem from the Israeli government regularly justify closures based on holidays. Also see Nanes (2017).

${ }^{15}$ Includes the most important Jewish holidays, Purim, Passover, Shavuot, Rosh Hashanah, Yom Kippur, and Sukkot, as well as two secular holidays, Yom Hazikaron (Remembrance Day) and Yom Ha'atzmaut (Independence Day). Holidays which span multiple days and are coded as "1" for any day on which the holiday is celebrated. Religious holidays that begin at sundown are also coded as "1" for the day before the holiday.
} 
in our context. Reese et al. (2017) suggest that terrorists avoid carrying out attacks on holidays for fear of upsetting their supporters by violating the holiness of the day. In the Israeli-Palestinian conflict, terrorists are overwhelmingly Muslim or Christian, whereas the holidays we use to predict closures are Jewish, thus terrorists are unlikely to worry about violating the day's sanctity. Similarly, Toft and Zhukov (2015) suggest that Islamist terrorists should rally around Muslim holidays, but our instrument is Jewish and secular holidays not celebrated by the attackers, and attacks are motivated by nationalism not religion. In the appendix we show that Palestinian holidays predict neither checkpoint closures nor terror attacks. Hassner (2011) argues that the appeal of attacking on holidays will only win out when rituals connected to the holiday undermine strategic defenses, which clearly is not the case in Israel given the increase in checkpoint closures.

Other links between holidays and terrorism imply that there should be more terrorism on holidays, biasing against our hypotheses. Terrorists may carry out more attacks on holidays because holidays serve as coordination points (Toft and Zhukov 2015) or because they increase attacks' strategic value (Hassner 2011). Such a trend would cancel out any negative effect of checkpoint closures on terrorism, biasing towards a null result. In terms of target availability, while closing stores, and restaurants on holidays reduces the number of viable targets, crowds gathered to celebrate present attractive targets for terrorists. Indeed, Israel has experienced a number of horrific attacks on holidays, including Hamas' bombing of a Passover celebration in 2002 which killed 30.

Finally, holidays might decrease the likelihood of attack through changes in security measures besides closing the barrier, for example extra patrols (Lucas 2019). To the extent that these additional measures deter attacks, they would amplify the apparent impact of comprehensive closures. This possible mechanism threatens the validity of our instrument. While we cannot rule it out entirely, we fail to find evidence of a link between terrorism and holidays between any mechanism other than checkpoint closures. We conduct two sets of placebo tests to systematically evaluate the validity of holidays as an instrument. First, 
we test the link between holidays and terrorism on days when checkpoints are open. A relationship would indicate that holidays are linked to terrorism through means other than checkpoint closures. Table 2 in the Appendix fails to find any such relationship, suggesting that holidays and terrorism are not significantly correlated through alternative channels. Second, we test whether Palestinian holidays are correlated with terrorist attacks. Since Palestinian holidays are not correlated with the likelihood of closure $\left(r^{2}=-.024\right)$, if they predict terror attacks it would suggest the presence of an alternative mechanism linking holidays of all kinds with terrorism. The results in Table 3 fail to show evidence of a relationship between Palestinian holidays and terror attacks. Overall, even though holidays and terrorism are unlikely to be perfectly exogenous, our instrumental variable approach improves substantially on a naive regression analysis.

Table 1 shows results from several models testing the relationship between checkpoint closures (wall porousness) and terrorist attacks. Unit of analysis is the day, covering January $1^{\text {st }}, 2000$ through December $31^{\text {st }}$, 2017. The dependent variable is the number of attacks by non-Jews ${ }^{16}$ which required the attacker to physically access the target, or in Model 3 whether at least one such attack occurred that day. These measures exclude rocket and mortar attacks, as well as a small number of sniper attacks, which cannot be stopped by checkpoint closures. ${ }^{17}$ We consider the type of weapon used in greater detail below. We control for several likely correlates of terrorism, including the number of Palestinian deaths caused by the Israeli military on the previous day, a dummy for whether the date falls during the Second Intifada, a dummy indicating whether the government in power is right-wing, and a count variable for the year to control for general time trends. Year also controls for decreases over time in permeability of the security barrier as construction progressed. Dummy variables for fall, winter, and spring account for seasonal trends in fighting.

Model 1 presents a negative binomial regression model testing the conditional effect

\footnotetext{
${ }^{16}$ Terrorism by Jewish Israelis is overwhelmingly motivated by goals other than Palestinian nationalism, and the barrier is not designed to stop these attacks, therefore we exclude them from the analysis.

${ }^{17}$ Replacing the dependent variable with projectile attacks yields a null result, as expected (see appendix).
} 
Table 1: Effects of Comprehensive Closures on Terrorist Attacks

\begin{tabular}{|c|c|c|c|c|c|}
\hline & $\begin{array}{c}(1) \\
\text { N. Bin. } \\
\text { Attacks }\end{array}$ & $\begin{array}{c}(2) \\
\text { 2SLS } \\
\text { Attacks }\end{array}$ & $\begin{array}{c}\text { (3) } \\
\text { 2SLS } \\
\text { Attack } 0 / 1\end{array}$ & $\begin{array}{c}(4) \\
\text { N. Bin. } \\
\text { Attacks IP }\end{array}$ & $\begin{array}{c}\text { (5) } \\
\text { N. Bin. } \\
\text { Attacks WB }\end{array}$ \\
\hline Closure & $\begin{array}{c}0.0670 \\
(0.0986)\end{array}$ & $\begin{array}{c}-0.259^{* * *} \\
(0.0678)\end{array}$ & $\begin{array}{c}-0.105^{* * *} \\
(0.0400)\end{array}$ & & \\
\hline Holiday & $\begin{array}{c}0.104 \\
(0.189)\end{array}$ & & & $\begin{array}{l}-0.248 \\
(0.235)\end{array}$ & $\begin{array}{c}0.195 \\
(0.201)\end{array}$ \\
\hline Closure x Holiday & $\begin{array}{c}-0.726^{* * *} \\
(0.272)\end{array}$ & & & & \\
\hline Days Since Reopen & & & & $\begin{array}{l}-0.00153^{* *} \\
(0.000627)\end{array}$ & $\begin{array}{c}0.00147^{* *} \\
(0.000658)\end{array}$ \\
\hline L.Pal. Deaths & $\begin{array}{l}0.206^{* * *} \\
(0.0390)\end{array}$ & $\begin{array}{c}0.0693^{* * *} \\
(0.0141)\end{array}$ & $\begin{array}{l}0.0351^{* * *} \\
(0.00771)\end{array}$ & $\begin{array}{l}0.601^{* * *} \\
(0.0382)\end{array}$ & $\begin{array}{l}0.241^{* * *} \\
(0.0622)\end{array}$ \\
\hline 2nd Intifada & $\begin{array}{c}1.644^{* * *} \\
(0.155)\end{array}$ & $\begin{array}{l}0.373^{* * *} \\
(0.0303)\end{array}$ & $\begin{array}{l}0.217^{* * *} \\
(0.0196)\end{array}$ & $\begin{array}{l}-0.118 \\
(0.150)\end{array}$ & $\begin{array}{c}1.604^{* * *} \\
(0.274)\end{array}$ \\
\hline Right & $\begin{array}{c}0.192^{* *} \\
(0.0817)\end{array}$ & $\begin{array}{c}0.0721^{* * *} \\
(0.0166)\end{array}$ & $\begin{array}{c}0.0519^{* * *} \\
(0.0108)\end{array}$ & $\begin{array}{c}-0.443^{* * *} \\
(0.0868)\end{array}$ & $\begin{array}{c}0.686^{* * *} \\
(0.143)\end{array}$ \\
\hline Year & $\begin{array}{l}0.134^{* * *} \\
(0.0144)\end{array}$ & $\begin{array}{l}0.0237^{* * *} \\
(0.00268)\end{array}$ & $\begin{array}{l}0.0132^{* * *} \\
(0.00183)\end{array}$ & $\begin{array}{c}0.0518^{* * *} \\
(0.0132)\end{array}$ & $\begin{array}{l}0.152^{* * *} \\
(0.0234)\end{array}$ \\
\hline Constant & $\begin{array}{c}-270.7^{* * *} \\
(28.99)\end{array}$ & $\begin{array}{c}-47.45^{* * *} \\
(5.387)\end{array}$ & $\begin{array}{c}-26.32^{* * *} \\
(3.683)\end{array}$ & $\begin{array}{c}-105.4^{* * *} \\
(26.52)\end{array}$ & $\begin{array}{c}-309.6^{* * *} \\
(47.08)\end{array}$ \\
\hline $\ln$ (alpha) & $\begin{array}{l}0.635^{* * *} \\
(0.0860)\end{array}$ & & & $\begin{array}{l}0.0563 \\
(0.142)\end{array}$ & $\begin{array}{c}0.977^{* * * *} \\
(0.123)\end{array}$ \\
\hline $\begin{array}{l}\text { Observations } \\
R^{2}\end{array}$ & 6302 & $\begin{array}{c}6302 \\
0.022\end{array}$ & $\begin{array}{c}6302 \\
0.031\end{array}$ & 5060 & 5060 \\
\hline
\end{tabular}

Models include season dummies. Robust SE in parentheses.

${ }^{*} p<.10,{ }^{* *} p<.05,{ }^{* * *} p<.01$ 
of checkpoint closures (measured directly) on the number of terror attacks in a given day. We make an initial attempt to isolate closures from the underlying threat of attack by interacting checkpoint closure status with whether the day was a holiday. While the likelihood of attack on non-holiday closures is not significantly different than the likelihood of attack on days when checkpoints are open, the expected number of attacks is significantly lower on closure days that are also holidays. Models 2 and 3 use the instrumental variable in 2SLS regression. We find a negative and significant relationship between the exogenous regressor and the likelihood of terror attacks: Model 3 predicts an 8.5 percentage point decrease in the likelihood that at least one terror attack occurs on a day when checkpoints are closed. Thus, at first glance, once we address endogeneity from the underlying threat of attack, evidence is consistent with the claim that checkpoint closures reduce the likelihood of terror attacks on a day-by-day basis.

Do closures cause an overall reduction in violence, or do they simply induce terrorists to wait until checkpoints reopen before attacking? Counterterrorism policies aside, terrorists should be relatively indifferent between dates within short windows, since Israeli violence responds to Palestinian violence, but not vice-versa (Jaeger and Paserman 2008). Thus, when the government uses security strategies which terrorists know to be temporary, attacks that would have occurred while checkpoints were closed should simply be delayed until checkpoints reopen.

Models 4 and 5 present results from regressions testing the relationship between time since the last closure and the likelihood of attack on days that checkpoints are open. We test this hypothesis separately for Israel Proper (Model 4) and the West Bank (Model 5), since we have no expectation that attackers originating on the West Bank side of the border who attack targets in the West Bank should wait for checkpoints to reopen, or that attackers originating in Israel Proper should seek to attack targets in the West Bank. We do not employ the instrumental variable in these regressions since we are comparing the likelihood of attack only across days on which checkpoints are open, which cannot be affected by 
Figure 3: Expected violence after checkpoints reopening
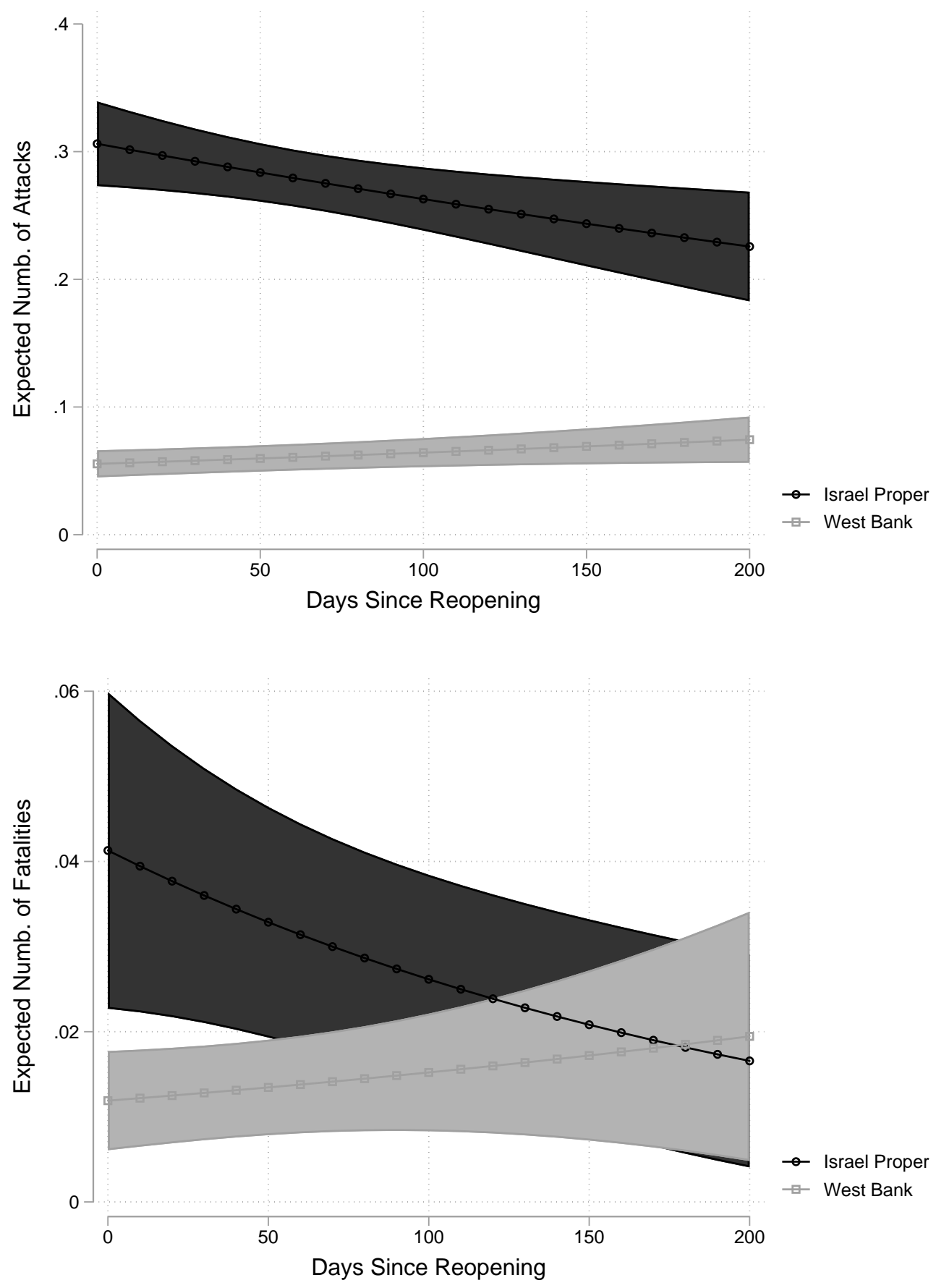

endogenously-determined closures.

Results show a small but significant decrease in the expected number of attacks in Israel Proper the longer it has been since the last checkpoint closure. We observe the opposite 
trend in the West Bank, with terror attacks becoming more likely as more time passes since a comprehensive closure, although in the appendix we show that this West Bank result is not robust to changes in model specifications. The top panel of Figure 3 shows that in Israel Proper, the expected number of attacks decreases by about 3.8\% percentage points, or more than $10 \%$ of baseline $(p<.01)$, from the day after reopening to three months later. ${ }^{18}$

This result may be attenuated for at least two reasons. First, the government may close checkpoints while it acts to apprehend or neutralize would-be attackers, reopening checkpoints only after the threat has been eliminated. Second, since terrorists do not know in advance the precise day on which checkpoints will reopen, they may require time after reopening to reorganize and carry out the planned attack. Both possibilities bias against our finding that the probability of attack in Israel Proper is highest immediately after checkpoints reopen.

Because we lack an observable counterfactual for the first day after a closure had there been no closure, we cannot say with certainty whether there are more attacks in the period immediately following a reopening than there would have been if the checkpoints had never closed. We also cannot say for sure whether the negative effect of closures on attacks is smaller or larger than any positive effect on attacks after reopening. Still, the observed pattern in which attacks are highest immediately after reopening, and only in areas to which closures prevent access, suggests that some terrorists respond to physical security by simply waiting to regain access to their preferred targets.

Gven the importance of terrorism's lethality, in the appendix we replicate Table 1 but substitute fatalities as the dependent variable. We fail to find a relationship between closures (instrumented or otherwise) and the expected number of fatalities overall. However, we do find a similar pattern regarding time since checkpoints reopened, with the expected number of fatalities in Israel Proper peaking immediately after checkpoints reopen (Bottom

\footnotetext{
${ }^{18} \mathrm{As}$ a placebo test, in the appendix we test the relationship between the number of days until the next closure and the likelihood of attack. Since terrorists cannot predict future closures, we should not observe a relationship between these variables, and indeed we do not observe one $(p>.90)$.
} 
panel of Figure 3).

Finally, as a placebo test we replicate the results above but use Palestinian, not Israeli holidays as the key predictor in each model (and in the first stage for the two-stage models). Whereas the correlation between closures and Israeli holidays is .31, the correlation between closures and Palestinian holidays is -.02. As expected, substituting Palestinian holidays as the instrument yields no apparent impact on the likelihood of terrorist attacks (See Appendix).

\section{Tactical Responses to Physical Security}

We now move from evaluating the barrier's impact on the likelihood of terror attacks to its impact on the nature of the conflict. In doing so, we change the unit of analysis from days to attacks. Walls are inherently better at stopping attacks using some weapons than others. For example, a wall may prevent attackers from smuggling a bomb from one side of the barrier to the other, but it cannot prevent rockets launched from one side from reaching targets on the other side. Following from this logic, terrorists should respond strategically to wall-building by turning to weapons that the wall cannot stop. Figure 4, which shows the distribution of attacks over time, hints at this long-term innovation. Between 2000 and 2005, when much of the security barrier remained under construction and the West BankIsrael Proper division was relatively porous, more than two-thirds of attacks used bombs or guns, most of which were smuggled into Israel Proper from the West Bank. Beginning in 2005, we observe a steady increase in the use of projectile attacks. As the security barrier's effectiveness in preventing would-be attackers and weapons from crossing from the West Bank into Israel Proper increased, organizations like Hamas and Palestinian Islamic Jihad invested in developing and stockpiling weapons which were not affected by the barrier (Getmansky and Zeitzoff 2014). In late 2012, Israel demonstrated that its new rocket defense system, Iron Dome, could effectively neutralize rockets and missiles. In response, attackers increasingly turned to "weapons of convenience" already present on both sides of the barrier like knives, 
cars, and molotov cocktails. 
Figure 4: Shifts in Attack Types Over Time

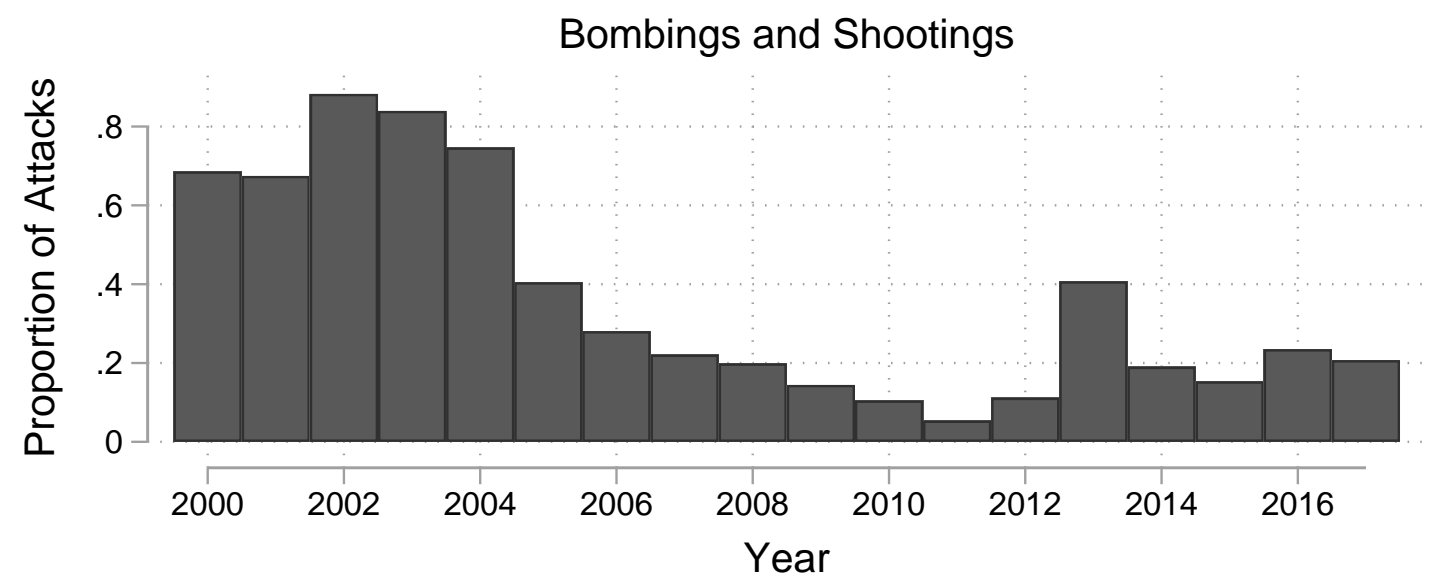

Rockets and Mortars

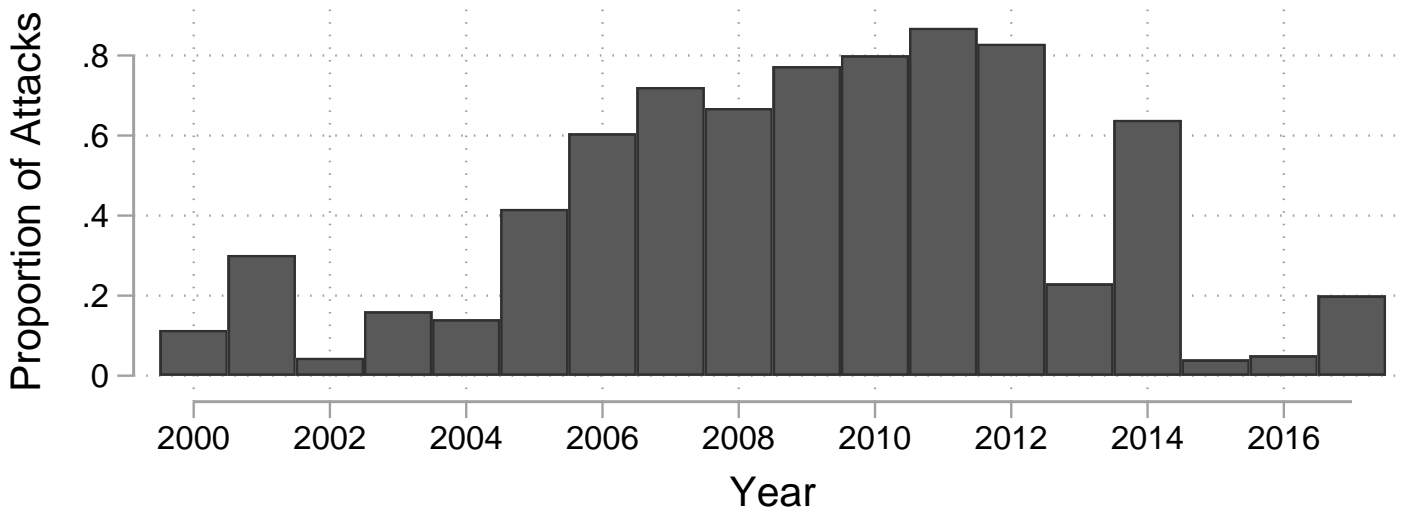

Convenience

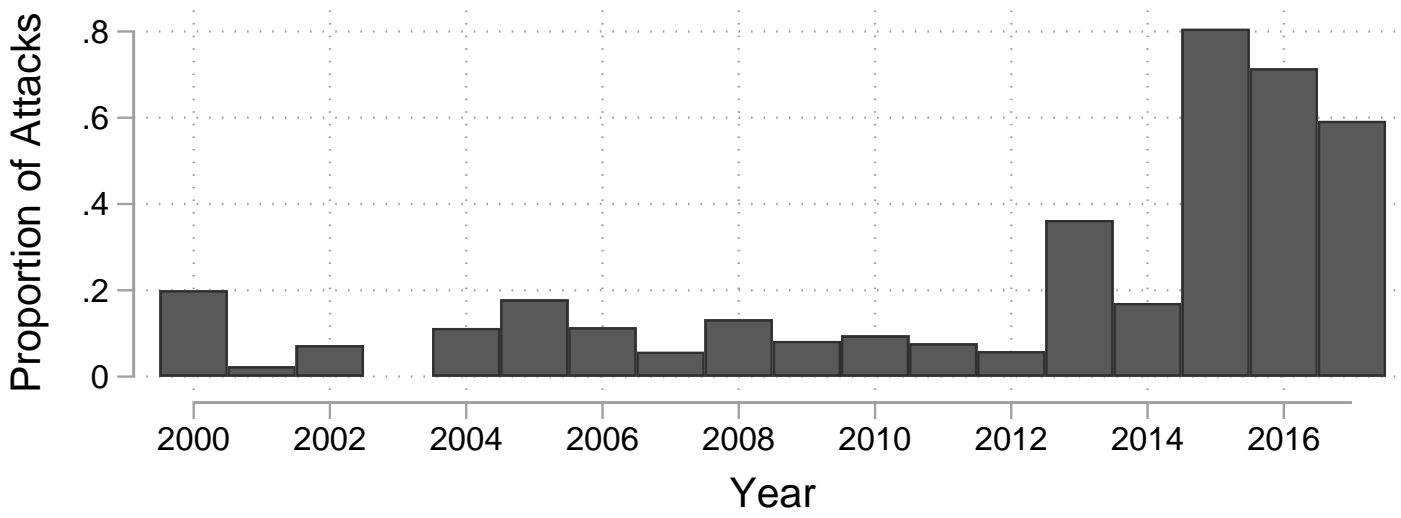


One way in which barriers change the short-term nature of illicit behavior is by incentivizing illicit actors to change their tactics, in this case by utilizing weapons that are not easily stymied by the barrier. Thus, when checkpoints are closed (i.e. the barrier is less porous), we expect to see an increase in the use of rockets and mortars, as well as weapons of convenience which do not need to be smuggled through checkpoints. We also expect an increase in the proportion of attacks that use suicide tactics when the checkpoints are closed. Suicide attacks are particularly costly for terrorist organizations because they kill the most dedicated operatives (Berman and Laitin 2005). Therefore, terrorists will only use suicide attacks when alternatives like non-suicide bombings or shootings are not available.

To test this argument, we test the effect of checkpoint closures on the type of weapon used, conditional on an attack occurring. Table 2 shows results from several models. As above, we control for whether the attack occurred during the Second Intifada, the logged number of Palestinian deaths caused by the Israeli military on the date in question, and year. We once again employ holidays as an instrument for checkpoint closures. We limit observations to attacks that occur in Israel Proper since the wall is designed to prevent these attacks. $^{19}$

Models 1, 2, and 3 display results related to terrorists' selections of weapons and tactics. Model 1 shows that among non-projectile attacks, terrorists substitute the type of weapon they use depending on whether checkpoints are closed by using weapons which are not easily stopped by closures. Consistent with attackers' need to smuggle "real" weapons like guns or bombs from the West Bank, attacks occurring when checkpoints are closed are more likely to use weapons of convenience like knives, vehicles, and molotov cocktails, and less likely to use more sophisticated weapons. Model 2 tests whether closures affect the likelihood that attacks use projectiles like rockets or mortars, which obviously cannot be stopped by checkpoints or walls. Surprisingly, we find no apparent relationship. One possible explanation is that by counting volleys of rockets rather than the number of rockets fired,

\footnotetext{
${ }^{19}$ Using the same models on the West Bank subset of attacks, the coefficient on Closure is indistinguishable from zero in all cases.
} 
Table 2: Effects of Comprehensive Closures on Nature of Attacks in Israel Proper

\begin{tabular}{lccccc}
\hline \hline & $(1)$ & $(2)$ & $(3)$ & $(4)$ & $(5)$ \\
& Convenience & Projectile & Suicide & Fatalities & Distance (IP) \\
\hline Closure & $0.559^{* * *}$ & 0.0578 & $0.734^{* * *}$ & 0.536 & $-1.727^{* *}$ \\
& $(0.207)$ & $(0.110)$ & $(0.270)$ & $(0.859)$ & $(0.763)$ \\
Second Intifada & 0.0315 & $-0.706^{* * *}$ & 0.0655 & $1.529^{* * *}$ & $-0.665^{* *}$ \\
& $(0.0904)$ & $(0.0554)$ & $(0.121)$ & $(0.343)$ & $(0.288)$ \\
Pal. Deaths & -0.0224 & $0.0505^{* * *}$ & 0.0249 & 0.0580 & 0.0581 \\
& $(0.0271)$ & $(0.00708)$ & $(0.0310)$ & $(0.0358)$ & $(0.0764)$ \\
Year & & & & $-0.118^{* * *}$ \\
& $0.0639^{* * *}$ & $-0.0313^{* * *}$ & $0.0368^{* * *}$ & -0.00575 & $(0.0270)$ \\
Location Certainty & $(0.00844)$ & $(0.00421)$ & $(0.00991)$ & $(0.0173)$ & $-0.160^{*}$ \\
& & & & & $(0.0934)$ \\
Constant & & & & & \\
& & & & & \\
\hline
\end{tabular}

Two-stage least squares regression with robust SE in parentheses.

${ }^{*} p<.10,{ }^{* *} p<.05,{ }^{* * *} p<.01$ 
our analysis misses relevant variation in the intensity of terrorist activity. Another possible explanation is that rockets and in-person attacks are carried out by different groups, and therefore they are not substitutes for one another. The overwhelming of rockets are fired by Hamas, while the majority of in-person attacks are perpetrated by the PLO, its splinter groups, and lone-wolves. Finally, most rocket attacks originate in Gaza, especially in the second half of the period of study. Closures primarily affect variation in access from the West Bank, so projectile attacks from Gaza introduce substantial noise into the data.

We find a positive and significant relationship between checkpoint closures and the proportion of in-person attacks using suicide tactics (Model 3). This finding is particularly striking for two reasons. First, the Israeli government built the barrier specifically to stop suicide bombers from targeting civilians in Israel Proper, and officials frequently tout the lower number of suicide attacks today compared to before the barrier's construction as evidence of its effectiveness. Yet, a more sophisticated analysis suggests that when physical security makes it more difficult to carry out attacks, terrorists are willing to take greater risks and sacrifice operatives for a chance at a successful operation. Second, suicide bombings are far and away the most lethal tactic, killing 16 times as many people per attack as stabbings in our data, and four times as many people as other attacks world-wide (Hoffman 2003). Even so, we find no evidence that reducing the barrier's porousness through checkpoint closures affects the overall fatality rate of an attack (given that an attack occurs). Model 4 uses fatalities per attack as the dependent variable; the coefficient on Closure is not distinguishable from zero.

Finally, we explore the logic that barriers should lead terrorists to attack different targets. Our preferred hypothesis would have been that terrorists are less likely to strike targets on the opposite side of the barrier from their home when checkpoints are closed. However, we were unable to identify the attacker's location of origin for about two-thirds of in-person attacks. Instead, we analyze the distance that in-person attacks occur from the security barrier itself. If the barrier makes it more difficult for terrorists to travel deep into 
Israel Proper without being detected, they may carry out their attacks in closer proximity to the barrier, or even attack the barrier itself. In Column 5, the dependent variable is the logged distance in meters of each attack in Israel Proper from the nearest point on the security barrier. In addition to the controls used in the previous models, we control for our certainty in location coding. ${ }^{20}$

We observe about a 1.5 standard deviation decrease in the distance of attacks from the security barrier on (instrumented) comprehensive closure days. ${ }^{21}$ Yet, a more detailed exploration of the data calls into question our suggestion that this trend is driven by attacks on checkpoints themselves. Across the entire dataset, only 6 in-person attacks occurred within 500 meters of the barrier. While 5 of the 6 indeed occurred on closure days, they cannot be driving the observed result. Rather, the relationship is driven by outliers at the high end. Of the 30 farthest attacks from the barrier, 28 occur on non-closure days, including both attacks in Eilat which are nearly twice as far from the barrier as the next-farthest attacks.

\footnotetext{
${ }^{20} 0=>2 k m, 1=$ between $1 k m$ and $2 k m, 2=<1 k m$

${ }^{21}$ As expected, we find no relationship between closures and attack location among attacks in the West Bank (not shown).
} 
Figure 5: Attacks when checkpoints are open

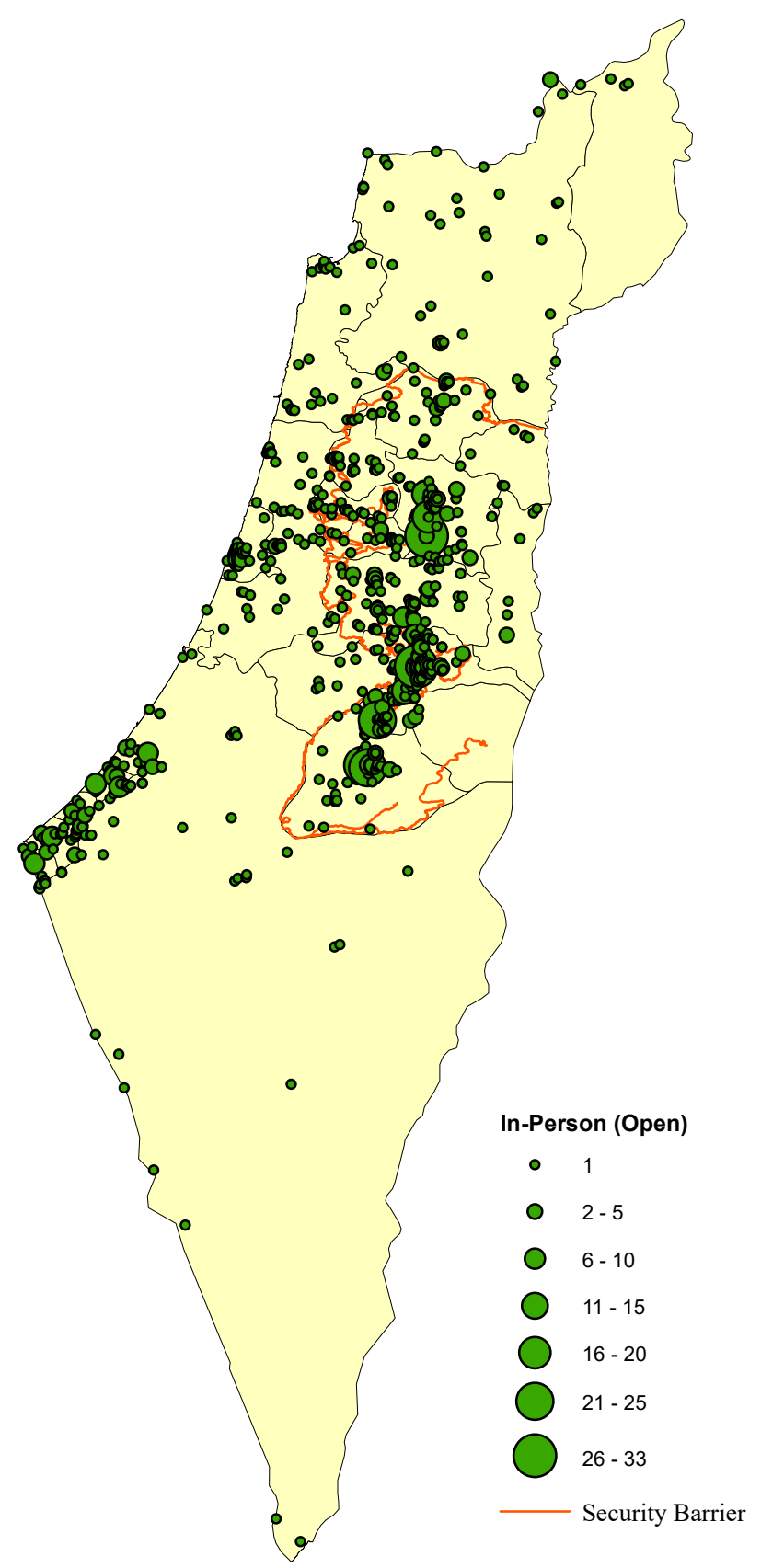


Figure 6: Attacks when checkpoints are closed

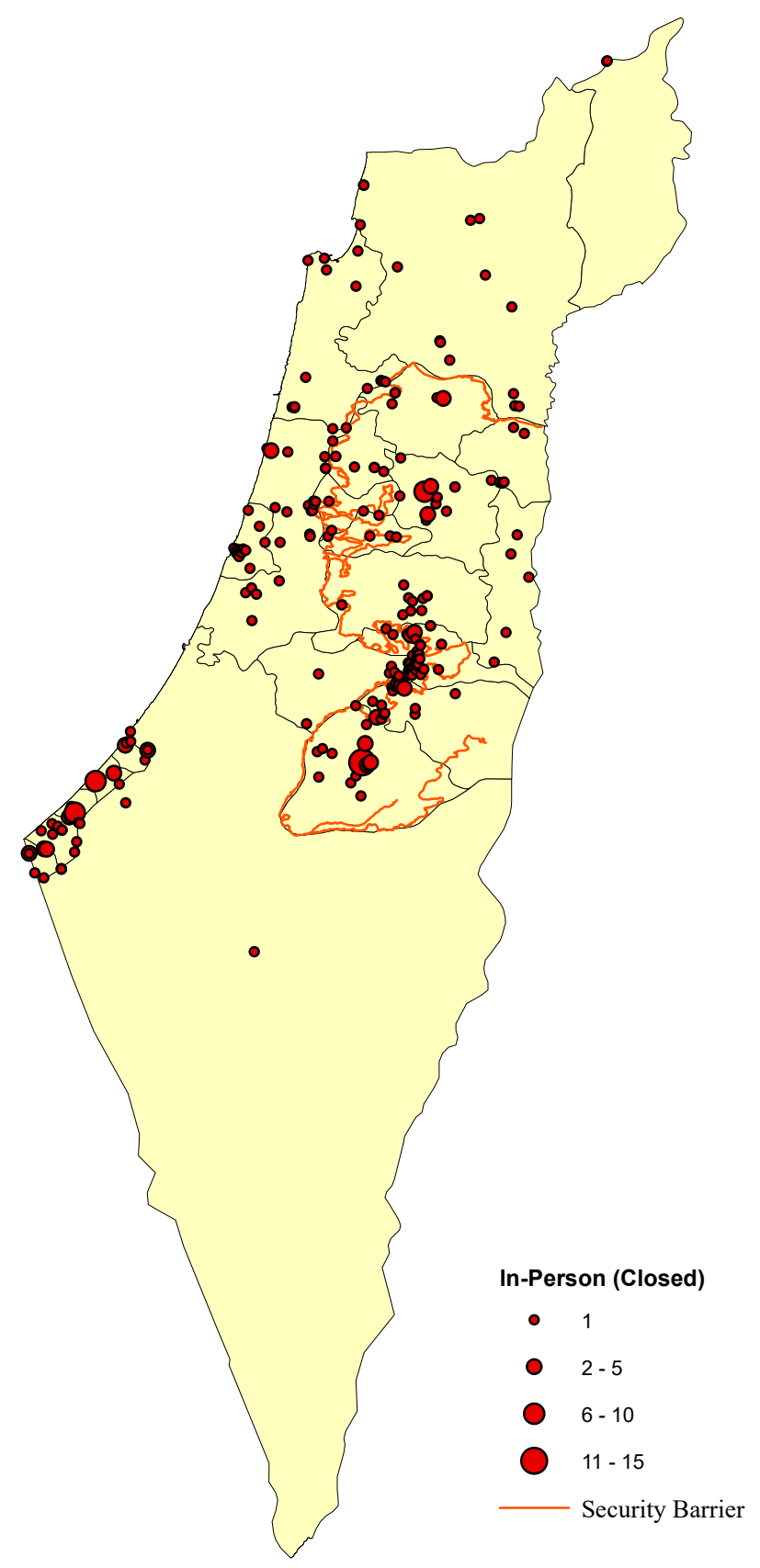

Further investigation shows that the apparent relationship between attack locations and closure days is endogenous to the group behind the attacks. Attacks not claimed by an organized group are far more likely when checkpoints are open, accounting for $72.0 \%$ of attacks on "open" days compared to $45.7 \%$ of attacks on "closure" days. Unclaimed and 
lone-wolf attacks are also substantially more likely to occur close to the security barrier. ${ }^{22}$ We speculate that this trend reflects the differing organizational capacities and time horizons between lone wolf attackers and organized groups. Lone wolves must travel to access their target. If doing so requires crossing the security barrier, their chances of success decrease dramatically when checkpoints are closed. Thus, closures either deter lone wolves or cause them to wait until checkpoints re-open. On the other hand, organized groups often spend weeks planning attacks, and may move weapons and operatives into place well before the attack takes place. Thus, in many cases the necessary resources may already be on the same side of the barrier as the target before the government closes the checkpoints, allowing the attack to proceed.

Finally, individuals who perpetrate attacks in the far north or south of the country rarely arrive directly via the West Bank. For example, in January 2007 a Gaza resident affiliated with Palestinian Islamic Jihad (PIJ) smuggled from Gaza into Egypt, then from Egypt into Israel, before detonating a bomb in a bakery in Eilat. The attack, which relied on the assistance of an organized group, would not have been affected by West Bank checkpoint closures. Similar attacks orchestrated by Hezbollah involve attackers sneaking across the northern border from Lebanon. Thus, the systematic shift in attack locations that we identify likely results from closures' disproportionate impact on would-be lone wolf attackers coming from the West Bank. The remaining attacks are carried out disproportionately by wellresourced organized groups operating in the country's far northern and southern reaches. Existing research attributes terrorists' target selection to their sources of support (Polo 2020). The wall's differential effects on organized versus lone-wolf terrorists suggests that target selection also depends on the way the government's counterterrorism policies affect different types of actors in different ways.

\footnotetext{
${ }^{22}$ Mean/Median distance $9,843 \mathrm{~m} / 4,067 \mathrm{~m}$ for lone wolf attackers; 21,233m/11,178m for organized groups
} 


\section{Discussion and Conclusion}

We find that decreasing the porousness of Israel's security barrier by closing checkpoints reduces the likelihood of terror attacks in Israel Proper as long as defensive measures remain in place. By leveraging the exogenous nature of holidays on checkpoint closures, we identify an 8.5 percentage point decrease in the likelihood that at least one attack occurs on days when checkpoints are closed. However, we also find evidence that terrorists respond strategically to physical security by altering when they attack, the targets they select, and the tactics they utilize.

Walls separate specific people from specific locations, but they do not solve underlying political issues which motivate violence. Strategic actors adapt and adjust their behavior in the face of physical barriers. To the broader question of whether walls "work," one way to operationalize terrorists' success (and therefore the wall's effectiveness) is through the lethality of tactics the wall pushes attackers to use. Although attacks are less likely when the barrier is less porous, we find no evidence of a corresponding reduction in fatalities, nor is there any evidence that attacks conducted when the barrier is less porous are any less lethal on average than those conducted when checkpoints allow movement. Furthermore, the Israeli government built the West Bank security barrier as an explicit response to suicide bombing and has repeatedly pointed to a decrease over time in the number of suicide bombings as evidence of the wall's effectiveness. Yet, our analysis reveals that when the barrier becomes less porous due to checkpoint closures, the proportion of attacks using suicide tactics increases.

Of course, terrorists' success need not be defined by the number of deaths they cause. Each volley of rocket or mortars in our data kills only 0.10 individuals. This low number is largely due to Israel's massive investment in the Iron Dome rocket defense system. Each of the nine missile batteries in the system costs about 100 million USD, and each time the system intercepts a rocket it costs an additional 50,000 USD or more. ${ }^{23}$ Rocket attacks force

\footnotetext{
${ }^{23}$ Morris, "Should Israel and the U.S. Rethink Iron Dome's Useful-
} 
the Israeli government to divert resources away from providing services like roads and schools, or away from other military uses. Furthermore, Israeli citizens living under the threat of rocket fire show signs of substantial psychological trauma despite the low likelihood of death (Shahar and Henrich 2019).

Finally, if walls incentivize terrorist innovation, they might actually perpetuate conflict. Innovation, whether in the form of developing new weapons technology, opening new smuggling routes, or re-thinking strategic tactics, usually entails startup costs. Just as successful businesses may become complacent by riding their current success rather than attempting to innovate, terrorist groups may avoid paying the startup costs of innovation unless changing conditions force them to do so. As Tilly (1993) points out, this innovation has the potential to change the nature of conflict over the long-term. Analyzing 18 years of data from a single conflict does not permit us to draw a conclusion on whether the wall helps or hinders a permanent end to fighting. However, the systematic evolution of terrorist tactics in both the short and long terms shows at the very least that the wall has changed the nature of the conflict. Governments like those in Israel, India, Morocco, Cyprus, the United States, and elsewhere which seek to use walls to reduce undesired movement must consider not just the wall's ability to block existing forms of movement but also the strategic responses of illicit actors in the future.

We do not, of course, propose that governments should never use walls or physical security. On the contrary, one of our main contributions is to empirically confirm that decreasing a wall's porousness reduces the likelihood of attacks. Rather, we point out that there may be a disconnect between walls' immediate impacts on illicit movement and a permanent solution to the underlying political problem. Governments should consider complementary strategies which fulfill their need to credit-claim in the short-term while also mitigating terrorists' strategic responses. After constructing a wall which interrupts illicit actors' operations, governments should seize on this moment of strength to bargain for a ness?" Los Angeles Times 21 August 2014, https://www.latimes.com/opinion/op-ed/ la-oe-morris-iron-dome-disastrous-for-israel-20140822-story.html 
permanent resolution to conflict. In this strategy, walls serve as a component of a broader political approach to solving the underlying issue. Second, if governments which use walls should simultaneously attempt to apprehend or eliminate key terrorist personnel, thereby not only interrupting existing plots but also reducing the group's ability to rebound and innovate.

\section{References}

Abrahams, A. (2019), 'Hard traveling: Unemployment and commuting in the shadow of political uncertainty'. https://www.dropbox.com/s/52jn1vsywh75vlh/hard_traveling_ june2019.pdf.

Aksoy, D. (2018), 'Electoral and partisan cycles in counterterrorism', The Journal of Politics 80(4), 1239-1253.

Berman, E. and Laitin, D. (2005), Hard targets: Theory and evidence on suicide attacks, Technical report, National Bureau of Economic Research.

Blattman, C., Green, D., Ortega, D. and Tobón, S. (2017), Place-based interventions at scale: The direct and spillover effects of policing and city services on crime, Technical report, National Bureau of Economic Research.

Bueno de Mesquita, E. (2007), 'Politics and the suboptimal provision of counterterror', International Organization 61(1), 9-36.

Carter, D. B. and Poast, P. (2017), 'Why do states build walls? Political economy, security, and border stability', Journal of conflict resolution 61(2), 239-270.

CPOST (2018), 'Suicide attack database', Chicago Project on Security and Threats .

Crenshaw, M. (1981), 'The causes of terrorism', Comparative politics 13(4), 379-399. 
Enders, W. and Sandler, T. (1993), 'The effectiveness of antiterrorism policies: A vectorautoregression-intervention analysis', American Political Science Review 87(4), 829-844.

Getmansky, A., Grossman, G. and Wright, A. L. (2019), 'Border walls and smuggling spillovers', Quarterly Journal of Political Science 14(3), 329-347.

Getmansky, A. and Zeitzoff, T. (2014), 'Terrorism and voting: The effect of rocket threat on voting in israeli elections', American Political Science Review 108, 588-604.

Harish, S. and Little, A. T. (2017), 'The political violence cycle', American Political Science Review 111(2), 237-255.

Hassner, R. E. (2011), 'Sacred time and conflict initiation', Security Studies 20(4), 491-520.

Hassner, R. E. and Wittenberg, J. (2015), 'Barriers to entry: Who builds fortified boundaries and why?', International Security 40(1), 157-190.

Hoffman, B. (2003), 'The logic of suicide terrorism'.

Jaeger, D. A. and Paserman, M. D. (2008), 'The cycle of violence? an empirical analysis of fatalities in the palestinian-israeli conflict', American Economic Review 98(4), 1591-1604.

Kronick, D. (2019), 'Profits and violence in illegal markets', Working paper .

Laughlin, B. (2019), 'Border fences and the mexican drug war', Working Paper.

Longo, M., Canetti, D. and Hite-Rubin, N. (2014), 'A checkpoint effect? evidence from a natural experiment on travel restrictions in the west bank', American Journal of Political Science.

Lucas, C. (2019), 'Deadly dates: The effect of holy days on terrorism', Presented at the Midwest Political Science Association Annual Meeting. Chicago: 4 April .

Nanes, M. J. (2017), 'Political violence cycles: Electoral incentives and the provision of counterterrorism', Comparative Political Studies 50(2), 171-199. 
Newman, G. R. and Clarke, R. V. (2008), Policing Terrorism: An Executive's Guide, US Department of Justice Office of Community Policing Services.

Polo, S. M. (2020), 'The quality of terrorist violence: Explaining the logic of terrorist target choice', Journal of peace research 57(2), 235-250.

Powell, R. (2007), 'Defending against terrorist attacks with limited resources', American Political Science Review 101(3), 527-541.

Reese, M. J., Ruby, K. G. and Pape, R. A. (2017), 'Days of action or restraint? How the Islamic calendar impacts violence', American Political Science Review 111(3), 439-459.

Shahar, G. and Henrich, C. C. (2019), 'Role of adolescent exposure to rockets in the links between personality vulnerability and psychopathology', Development and psychopathology 31(4), 1367-1380.

Spencer, J. (2016), 'The most effective weapon on the modern battlefield is concrete', RealClear Defense. https://www.realcleardefense.com/articles/2016/11/15/the_ most_effective_weapon_on_the_modern_battlefield_is_concrete_110348.html.

START (2018), 'Global terrorism database', National Consortium for the Study of Terrorism and Responses to Terrorism . https://www.start.umd.edu/gtd.

Thein, B. (2004), 'Is Israel's security barrier unique?', Middle East Quarterly .

Tilly, C. (1993), 'Contentious repertoires in Great Britain, 1758-1834', Social Science History $\mathbf{1 7}(2), 253-280$.

Toft, M. D. and Zhukov, Y. M. (2015), 'Islamists and nationalists: Rebel motivation and counterinsurgency in Russia's North Caucasus', American Political Science Review $\mathbf{1 0 9}(2), 222-238$. 


\section{A Data Description and Coding Rules}

To be included in our dataset, an incident must (a) occur in Israel Proper (any territory governed by Israeli civilian rule, regardless of disputed status), the West Bank, or Gaza, (b) involve a premeditated attempt to destroy life or property, and (c) be committed by a non-state actor motivated by political goals.

We began with all incidents reported in the Global Terrorism Database and the Chicago Project on Security and Threats dataset. We eliminated incidents that did not meet our criteria for inclusion, primarily protests and tire-burning which were not clearly incidents of violence and do not meet most commonly-used definitions of terrorism. We also excluded a number of incidents in which security forces eliminated terrorist threats before terrorists could attempt to carry out their attack. However, incidents in which terrorists were foiled in the process of attempting to carry out an attack remain in the dataset.

In addition, we conducted a comprehensive search of all mentions of terrorism in the Jerusalem Post, a major English-language Israeli newspaper, which we accessed electronically via LexusNexus. We searched all articles published between January 1st, 2000 and December 31st, 2017 for the keywords "terror," "knife," "stabbing," "bombing," and "shooting." This search returned over 100,000 articles. One of the authors read each headline and, if it appeared relevant, the entire article. If the article mentioned a terrorist attack that was not already included in GTD or CPOST, we added it to our dataset. All-told, we identify 1600 attacks in these sources in which attackers were present, roughly consistent with official Israeli statistics.

After identifying the dates and approximate locations of all attacks, we conducted additional research to identify each attack's precise location, weapon used, group claiming credit (if applicable), and the attacker's home neighborhood where available, drawing data from newspaper articles and other resources available online. While entries in GTD frequently include location coordinates, these tend to be very coarsely identified, often only to the nearest large city. We sought to identify the attack's location with as much precision 
as possible. Since the quality of accounts varied across attacks, we code for the certainty of our precision of the attack location. In $67.1 \%$ of our sample, we are certain of the attack location within 1,000 meters. We locate an additional 15.8\% between 1,000 and 2,000 meters of certainty, and the remaining $17.1 \%$ beyond 2,000 meters of certainty (typically meaning we could determine only the nearest major city). Of the 273 attacks with certainty greater than 2000 meters, 78.8\% occurred in Gaza or the West Bank. In other words, our geocoding within Israel Proper, which we use to test geographic displacement, is precise in an overwhelming majority of cases. We were able to identify the attacker's home town in $32.7 \%$ of attacks. Of these observations, several towns accounted for a disproportionate number of attackers: 85 from Hebron, 46 from Nablus, and 28 from Jenin. Finally, 77\% of the attacks were successful, meaning that the attacker succeeded in accessing his or her target and deploying his or her weapon.

There is some concern that our reliance on news sources could lead us to miss or find fewer details about attacks that occur on holidays. For example, fewer reporters could be working on those days, or attacks compete for reporting space with other stories. The Israeli government's tendency to ensure that the media reports all terror attacks mitigates this concern. To the extent that Israel wishes to portray itself as a victim of horrendous violence, therefore justifying its strict security policies, reporting all attacks against civilians serves its political goals and reduces the likelihood that the quality or completeness of our data would vary across days.

Our reliance on news sources likely biases our dataset in favor of more extreme incidents, both in terms of fatalities and the profile of the target. We fail to capture much of the low-level violence that characterizes daily tensions in some locations, especially around Jewish settlements in the West Bank. Rock-throwing, minor arson, and non-fatal violence towards civilians and security officials from both sides rarely finds its way into the news sources on which we rely. This exclusion limits the uses of our dataset, but poses little problem for our ability to test the hypotheses in this paper. The "extreme" incidents that are 
most likely to appear in our dataset are the incidents about which the government should care most, as they are the most likely to influence citizens' evaluations of government security provision. For the same reason, terrorists benefit most from high-profile attacks that make the news, therefore the frequency and nature of these attacks is most relevant to the strategic interactions between terrorists and the target government.

Our figures diverge from the Israeli government's statistics on terror attacks as we exclude tire burning and demonstrations. The government also includes incidents in which security services apprehended terrorists before they perpetrated an attack. We do not include these incidents, as no attack occurred. 


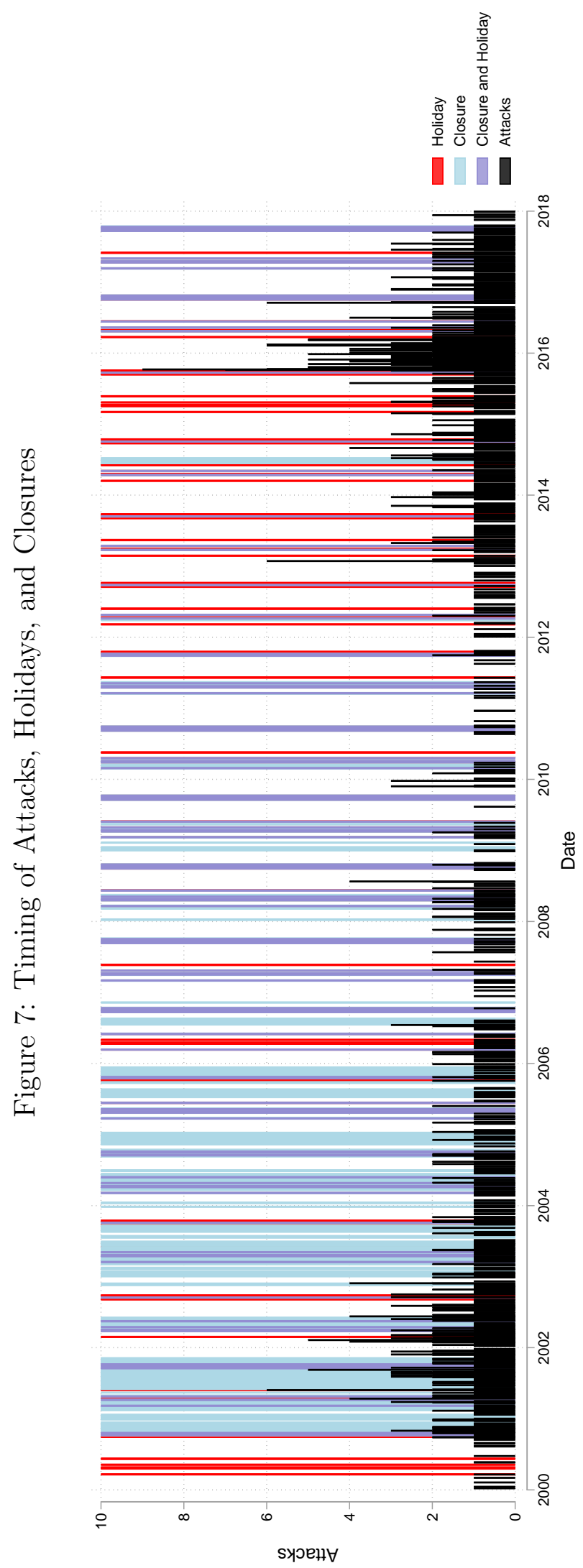


Table 3: Attacker Affiliation

\begin{tabular}{lll}
\hline Group & Frequency & Percent \\
\hline Hamas & 409 & 15.2 \\
Fatah & 130 & 4.8 \\
Tanzim & 4 & 0.2 \\
Al Aqsa Martyrs & 126 & 4.7 \\
PFLP & 26 & 1.0 \\
Abu Ali Mustafa Brigade & 2 & 0.1 \\
Jihad Jibril & 1 & 0.1 \\
DFLP & 8 & 0.3 \\
Islamic Jihad & 186 & 6.9 \\
al Quds & 7 & 0.3 \\
Hizbollah & 44 & 1.6 \\
Popular Resistance Committee & 62 & 2.3 \\
al-Qaeda & 42 & 1.6 \\
Islamic State & 18 & 0.7 \\
Qassim Brigades & 13 & 0.5 \\
Lone Wolf / Unclaimed & 1,600 & 59.3 \\
Multiple Groups & 15 & 0.6 \\
Organized Jewish Groups & 4 & 0.2 \\
Unknown & 22 & 0.7 \\
\hline
\end{tabular}

\section{B Exclusion Restriction and First Stage Results}

To test whether holidays affect the likelihood of terrorism through a mechanism other than checkpoint closures, which would violate the exclusion restriction, Table 4 presents regression models which test the impacts of holidays on the likelihood of terrorism for the subset of days on which checkpoints are open. The dependent variable is the number of attacks on a given day (limited to attacks which require the attacker to access the target). Model 1 tests the effects of holidays for all attacks in the dataset, Model 2 for those occurring in Israel Proper, and Model 3 for those occurring in the West Bank. In no case is Holiday significantly related to the number of terrorist attacks. This lack of correlation is consistent with holidays meeting the exclusion restriction as a valid instrument.

Table 5 uses Palestinian holidays as an instrument for closures. We include days 
Table 4: Effects of Holidays on Terrorist Attacks when Checkpoints Open

\begin{tabular}{|c|c|c|c|}
\hline & $\begin{array}{c}(1) \\
\text { All Attacks } \\
\end{array}$ & $\begin{array}{c}(2) \\
\text { IP Only }\end{array}$ & $\begin{array}{c}(3) \\
\text { WB Only }\end{array}$ \\
\hline Holiday & $\begin{array}{l}0.0739 \\
(0.193)\end{array}$ & $\begin{array}{l}-0.247 \\
(0.236)\end{array}$ & $\begin{array}{c}0.257 \\
(0.186)\end{array}$ \\
\hline L.Pal. Deaths & $\begin{array}{l}0.253^{* * *} \\
(0.0443)\end{array}$ & $\begin{array}{l}0.612^{* * *} \\
(0.0382)\end{array}$ & $\begin{array}{l}0.234^{* * *} \\
(0.0594)\end{array}$ \\
\hline 2nd Intifada & $\begin{array}{c}1.717^{* * *} \\
(0.183)\end{array}$ & $\begin{array}{l}-0.169 \\
(0.149)\end{array}$ & $\begin{array}{c}1.599^{* * *} \\
(0.268)\end{array}$ \\
\hline Right & $\begin{array}{l}0.433^{* * *} \\
(0.0960)\end{array}$ & $\begin{array}{c}-0.425^{* * *} \\
(0.0869)\end{array}$ & $\begin{array}{c}0.600^{* * *} \\
(0.140)\end{array}$ \\
\hline Year & $\begin{array}{l}0.140^{* * *} \\
(0.0159)\end{array}$ & $\begin{array}{c}0.0426^{* * *} \\
(0.0126)\end{array}$ & $\begin{array}{l}0.165^{* * *} \\
(0.0226)\end{array}$ \\
\hline Constant & $\begin{array}{c}-283.2^{* * *} \\
(31.96)\end{array}$ & $\begin{array}{c}-87.13^{* * *} \\
(25.38) \\
\end{array}$ & $\begin{array}{c}-334.5^{* * *} \\
(45.42) \\
\end{array}$ \\
\hline $\ln ($ alpha $)$ & $\begin{array}{l}0.630^{* * *} \\
(0.0976)\end{array}$ & $\begin{array}{l}0.0727 \\
(0.142)\end{array}$ & $\begin{array}{c}0.934^{* * *} \\
(0.120)\end{array}$ \\
\hline Observations & 5066 & 5066 & 5066 \\
\hline
\end{tabular}


declared as public holidays by the Palestinian Authority (Land Day, Isra and Miraj, Eid al-Fitr, Eid al-Adha, Islamic New Year, Mawlid, Independence Day, Solidarity Day, and Christmas), as well as Ramadan and Ashura. Since Palestinian holidays are not correlated with the likelihood of closure $\left(r^{2}=-.024\right)$, if they predict terror attacks it would suggest a potential violation of the exclusion restriction. Models in Table 5 fail to find evidence of any such relationship.

Table 6 shows first-stage results for the instrumental variable analysis, probing the relationship between Holiday and the endogenous regressor Closure. Both variables are zeroone indicators. The first column shows a positive and significant relationship between the two variables using OLS with robust standard errors. Model 2 adds controls for government partisanship, election timing, and their interaction, which existing research suggests are important predictors of a government's choice of counterterrorism policies (Nanes 2017; Aksoy 2018). Model 3 adds controls for whether the day occurred during the Second Intifada, the number of Palestinian deaths from Israeli military action on the previous day, and the year, to account for possible endogeneity from time trends, the overall level of conflict during the period in question, or both. Model 4 includes both sets of controls. As Model 4 explains the highest level of variance in Closures, we use it in the 2SLS models presented in Table 1 in the main text. However, later in this appendix, we show that the results are robust to excluding controls in both the first and second stages. 
Table 5: Effects of Comprehensive Closures on Terrorist Attacks (Pal. Holidays)

\begin{tabular}{lccccc}
\hline \hline & $(1)$ & $(2)$ & $(3)$ & $(4)$ & $(5)$ \\
& N. Bin. & 2SLS & 2SLS & N. Bin. & N. Bin. \\
& Attacks & Attacks & Attack 0/1 & Attacks IP & Attacks WB \\
\hline Closure & & & & & \\
& -0.0805 & 1.561 & 0.223 & & \\
Pal. Holiday & $(0.0964)$ & $(2.131)$ & $(0.966)$ & & \\
& -0.0886 & & & 0.153 & -0.188 \\
Clos. X Pal. Holiday & $(0.108)$ & & & $(0.102)$ & $(0.156)$ \\
& 0.0626 & & & & \\
Days Since Reopen & $(0.247)$ & & & & \\
& & & & $-0.00151^{* *}$ & $0.00146^{* *}$ \\
L.Pal. Deaths & & & & $(0.000625)$ & $(0.000662)$ \\
& $0.208^{* * *}$ & 0.0392 & $0.0297^{*}$ & $0.596^{* * *}$ & $0.242^{* * *}$ \\
2nd Intifada & $(0.0396)$ & $(0.0389)$ & $(0.0179)$ & $(0.0384)$ & $(0.0625)$ \\
& $1.672^{* * *}$ & 0.0521 & 0.160 & -0.135 & $1.612^{* * *}$ \\
Right & $(0.154)$ & $(0.376)$ & $(0.171)$ & $(0.150)$ & $(0.274)$ \\
& & & & & \\
& $0.208^{* *}$ & -0.0196 & 0.0354 & $-0.449^{* * *}$ & $0.690^{* * *}$ \\
Year & $(0.0817)$ & $(0.109)$ & $(0.0497)$ & $(0.0868)$ & $(0.143)$ \\
& & & & & \\
Constant & $0.132^{* * *}$ & 0.0631 & 0.0203 & $0.0509^{* * *}$ & $0.152^{* * *}$ \\
& $(0.0143)$ & $(0.0465)$ & $(0.0210)$ & $(0.0132)$ & $(0.0235)$ \\
\hline ln(alpha) & $-266.5^{* * *}$ & -126.8 & -40.63 & $-103.6^{* * *}$ & $-308.4^{* * *}$ \\
\hline \hline Observations & $(28.84)$ & $(93.70)$ & $(42.27)$ & $(26.48)$ & $(47.16)$ \\
\hline \hline
\end{tabular}

Models include season dummies. Robust SE in parentheses.

${ }^{*} p<.10,{ }^{* *} p<.05,{ }^{* * *} p<.01$ 
Table 6: First Stage - Holidays and Comprehensive Closures

\begin{tabular}{|c|c|c|c|c|}
\hline & (1) & (2) & (3) & (4) \\
\hline \multirow[t]{2}{*}{ Holiday } & $0.454^{* * *}$ & $0.457^{* * *}$ & $0.467^{* * *}$ & $0.467^{* * *}$ \\
\hline & $(0.0223)$ & $(0.0222)$ & $(0.0224)$ & $(0.0223)$ \\
\hline \multirow[t]{2}{*}{ Right } & & 0.0102 & & $0.113^{* * *}$ \\
\hline & & $(0.0174)$ & & $(0.0160)$ \\
\hline \multirow[t]{2}{*}{ Days to Election } & & $-0.0000394^{* * *}$ & & $0.0000574^{* * *}$ \\
\hline & & $(0.0000151)$ & & $(0.0000151)$ \\
\hline \multirow[t]{2}{*}{ Right $\times$ Days to Election } & & -0.0000251 & & $-0.000105^{* * *}$ \\
\hline & & $(0.0000226)$ & & $(0.0000210)$ \\
\hline \multirow[t]{2}{*}{ 2nd Intifada } & & & $0.202^{* * *}$ & $0.196^{* * *}$ \\
\hline & & & $(0.0177)$ & $(0.0213)$ \\
\hline \multirow[t]{2}{*}{ Pal. Deaths (lag) } & & & $0.0197^{* * *}$ & $0.0218^{* * *}$ \\
\hline & & & $(0.00716)$ & $(0.00719)$ \\
\hline \multirow[t]{2}{*}{ Year } & & & $-0.0178^{* * *}$ & $-0.0199^{* * *}$ \\
\hline & & & $(0.00120)$ & $(0.00174)$ \\
\hline \multirow[t]{2}{*}{ Constant } & $0.153^{* * *}$ & $0.179^{* * *}$ & $35.95^{* * *}$ & $40.11^{* * *}$ \\
\hline & $(0.00462)$ & $(0.0109)$ & $(2.413)$ & $(3.508)$ \\
\hline Observations & 6575 & 6575 & 6302 & 6302 \\
\hline$R^{2}$ & 0.095 & 0.098 & 0.283 & 0.289 \\
\hline
\end{tabular}

Dependent variable is comprehensive closure (1/0). OLS with robust SE in parentheses.

${ }^{*} p<.10,{ }^{* *} p<.05,{ }^{* * *} p<.01$ 


\section{Impact of Wall Porousness on Fatalities}

Fatalities from terrorism are a function of terrorists' effort, government security (including the barrier's porousness and other measures), victims' underlying health conditions, vehicle and pedestrian traffic, terrorists' skills with their weapons, and a variety of other factors, many of which have little to do with a barrier's effectiveness. Factors like pedestrian traffic and victims' underlying health cause variation in the number of fatalities an attack causes, given that it occurs. In contrast, walls are designed to prevent fatalities by preventing attacks in the first place, especially attacks which use sophisticated weapons. Thus, the number and type of attacks are a more precise metric on which to evaluate a barrier than the number of deaths caused by terrorism.

Still, there is no denying the importance of attacks' lethality. Terrorists claim bigger headlines and impose greater fear when they kill more civilians, and governments look weaker when they are unable to prevent deaths. Thus, we explore the barrier's impact on fatalities here. We expect the patterns to be similar to those presented in the main text, but less precisely estimated given the additional factors which impact fatality rates per attack.

Table 7 replicates the results of Table 1 but substitutes the number of terror fatalities in a day as the dependent variable (rather than the number of attacks in a day). As in the main text, the naive regression fails to find evidence of a relationship between closures and terror fatalities (Model 1). Model 2 shows a positive conditional relationship between instrumented closures and terror fatalities, but the relationship is not statistically distinguishable from zero. On the other hand, Models 3 and 4 show a very similar relationship between time since reopening and fatalities, compared to time since reopening and the probability of attack. In Israel Proper, among days when checkpoints are open, the highest number of expected fatalities occurs immediately following the end of a closure, and expected fatalities decrease the longer checkpoints remain open. In the West Banks, there is no significant relationship between days since reopening and expected fatalities. We illustrate this relationship in the bottom panel of Figure 3 in the main text. Table 2, Column 4 in the main text fails 
to find evidence of a relationship between closures (wall porousness) and the number of fatalities an attack causes.

Table 7: Effects of Comprehensive Closures on Terror Fatalities

\begin{tabular}{|c|c|c|c|c|}
\hline & $\begin{array}{c}(1) \\
\text { N. Bin. }\end{array}$ & $\begin{array}{c}(2) \\
2 \text { SLS }\end{array}$ & $\begin{array}{c}(3) \\
\text { N. Bin. IP }\end{array}$ & $\begin{array}{c}(4) \\
\text { N. Bin. WB }\end{array}$ \\
\hline Closure & $\begin{array}{c}0.268 \\
(0.229)\end{array}$ & $\begin{array}{l}0.0265 \\
(0.180)\end{array}$ & & \\
\hline Holiday & $\begin{array}{c}0.499 \\
(0.544)\end{array}$ & & $\begin{array}{c}0.776 \\
(0.764)\end{array}$ & $\begin{array}{c}0.106 \\
(0.497)\end{array}$ \\
\hline Closure x Holiday & $\begin{array}{l}-0.756 \\
(0.686)\end{array}$ & & & \\
\hline Days Since Reopen & & & $\begin{array}{c}-0.00457^{* *} \\
(0.00208)\end{array}$ & $\begin{array}{c}0.00246 \\
(0.00227)\end{array}$ \\
\hline L.Pal. Deaths & $\begin{array}{l}0.357^{* * *} \\
(0.0777)\end{array}$ & $\begin{array}{l}0.0758^{* *} \\
(0.0321)\end{array}$ & $\begin{array}{c}0.546^{* * *} \\
(0.113)\end{array}$ & $\begin{array}{c}0.145 \\
(0.179)\end{array}$ \\
\hline 2nd Intifada & $\begin{array}{c}1.484^{* * *} \\
(0.287)\end{array}$ & $\begin{array}{l}0.482^{* * *} \\
(0.0774)\end{array}$ & $\begin{array}{c}1.640^{* * *} \\
(0.458)\end{array}$ & $\begin{array}{c}2.214^{* * *} \\
(0.520)\end{array}$ \\
\hline Right & $\begin{array}{c}0.287 \\
(0.182)\end{array}$ & $\begin{array}{l}-0.0664 \\
(0.0437)\end{array}$ & $\begin{array}{c}0.149 \\
(0.306)\end{array}$ & $\begin{array}{l}0.779^{* *} \\
(0.381)\end{array}$ \\
\hline Year & $\begin{array}{c}-0.0697^{* *} \\
(0.0301)\end{array}$ & $\begin{array}{l}0.000609 \\
(0.00584)\end{array}$ & $\begin{array}{l}-0.0683 \\
(0.0486)\end{array}$ & $\begin{array}{l}-0.0234 \\
(0.0577)\end{array}$ \\
\hline Constant & $\begin{array}{l}137.5^{* *} \\
(60.54)\end{array}$ & $\begin{array}{l}-1.083 \\
(11.74)\end{array}$ & $\begin{array}{c}134.3 \\
(97.66)\end{array}$ & $\begin{array}{c}42.71 \\
(116.0)\end{array}$ \\
\hline $\ln ($ alpha $)$ & $\begin{array}{l}3.083^{* * *} \\
(0.0832)\end{array}$ & & $\begin{array}{c}3.890^{* * *} \\
(0.136)\end{array}$ & $\begin{array}{c}3.829^{* * *} \\
(0.159)\end{array}$ \\
\hline $\begin{array}{l}\text { Observations } \\
R^{2}\end{array}$ & 6302 & $\begin{array}{l}6302 \\
0.032\end{array}$ & 5060 & 5060 \\
\hline
\end{tabular}

Models include season dummies. Robust SE in parentheses.

${ }^{*} p<.10,{ }^{* *} p<.05,{ }^{* * *} p<.01$ 


\section{Robustness}

The models in Table 1, Columns 1, 4, and 5 use negative binomial regression due to the overdispersed distribution of the count dependent variable, the number of terrorist attack occurring in a day. To aid in comparing coefficients across 2SLS and non-instrumented regression models, we replicate Table 1 below using OLS instead of negative binomial regression in Columns 1, 4, and 5. Negative binomial is unquestionably the more appropriate model for this data. Still, it is encouraging to see that the interaction coefficient between Closure and Holiday remains negative and significant, as does the coefficient on days since checkpoints reopened in Column 4. In Column 5, the effect of days since checkpoints reopening on terror attacks in the West Bank loses significance, likely due to the model's poorer fit. Still, the results support the general argument that terrorists concentrate attacks in Israel Proper shortly after checkpoints reopen from a closure.

Table 9 reproduces Table 1 in the main text but excludes all control variables except the year trend. Overall, results are robust to this change in specification.

Table 10, Model 1 tests the relationship between closures and in-person terror attacks using a naive regression that does not account for the endogenous declaration of closures when the threat of attack is highest. As expected, and unlike the results in Table 1, we find a misleading null result. Models 2 and 3 test the effect of closures on the number of projectile attacks each day. Since the security barrier cannot stop rockets and mortars from being launched into Israel Proper, checkpoint closures should not be associated with a decrease in projectile attacks. Model 2 includes an interaction between whether checkpoints are closed and whether the date is a holiday (i.e. checkpoints are likely closed for non-strategic reasons). While closures are associated with more projectile attacks on non-holidays, the expected number of attacks on holiday-closure days is not significantly different than day on which checkpoints are open. Model 3, which uses holidays as an instrument for closures, finds a similar null result.

Model 4 is a placebo test on the effects of timing on attacks. We show in Table 1 that 
Table 8: Effects of Comprehensive Closures on Terrorist Attacks

\begin{tabular}{|c|c|c|c|c|c|}
\hline & $\begin{array}{c}\text { (1) } \\
\text { OLS } \\
\text { Attacks }\end{array}$ & $\begin{array}{c}(2) \\
\text { 2SLS } \\
\text { Attacks }\end{array}$ & $\begin{array}{c}(3) \\
\text { 2SLS } \\
\text { Attack 0/1 }\end{array}$ & $\begin{array}{c}(4) \\
\text { OLS } \\
\text { Attacks IP }\end{array}$ & $\begin{array}{c}5) \\
\text { OLS } \\
\text { Attacks WB }\end{array}$ \\
\hline Closure & $\begin{array}{c}0.00887 \\
(0.0244)\end{array}$ & $\begin{array}{c}-0.180^{* * *} \\
(0.0571)\end{array}$ & $\begin{array}{c}-0.0851^{* *} \\
(0.0356)\end{array}$ & & \\
\hline Holiday & $\begin{array}{c}0.0205 \\
(0.0541)\end{array}$ & & & $\begin{array}{l}-0.0475 \\
(0.0425)\end{array}$ & $\begin{array}{c}0.0317 \\
(0.0376)\end{array}$ \\
\hline Closure x Holiday & $\begin{array}{c}-0.124^{* *} \\
(0.0623)\end{array}$ & & & & \\
\hline Days Since Reopen & & & & $\begin{array}{c}-0.000479^{* * *} \\
(0.000151)\end{array}$ & $\begin{array}{c}0.000168 \\
(0.000150)\end{array}$ \\
\hline L.Pal. Deaths & $\begin{array}{c}0.0652^{* * *} \\
(0.0138)\end{array}$ & $\begin{array}{c}0.0682^{* * *} \\
(0.0140)\end{array}$ & $\begin{array}{l}0.0347^{* * *} \\
(0.00770)\end{array}$ & $\begin{array}{l}0.332^{* * *} \\
(0.0455)\end{array}$ & $\begin{array}{c}0.0441^{* * *} \\
(0.0118)\end{array}$ \\
\hline 2nd Intifada & $\begin{array}{c}0.325^{* * *} \\
(0.0270)\end{array}$ & $\begin{array}{l}0.358^{* * *} \\
(0.0287)\end{array}$ & $\begin{array}{l}0.213^{* * *} \\
(0.0189)\end{array}$ & $\begin{array}{c}-0.0999^{* * *} \\
(0.0334)\end{array}$ & $\begin{array}{l}0.177^{* * *} \\
(0.0251)\end{array}$ \\
\hline Right & $\begin{array}{c}0.0563^{* * *} \\
(0.0154)\end{array}$ & $\begin{array}{c}0.0686^{* * *} \\
(0.0162)\end{array}$ & $\begin{array}{c}0.0518^{* * *} \\
(0.0107)\end{array}$ & $\begin{array}{c}-0.0688^{* * *} \\
(0.0201)\end{array}$ & $\begin{array}{c}0.0938^{* * *} \\
(0.0139)\end{array}$ \\
\hline Year & $\begin{array}{l}0.0292^{* * *} \\
(0.00264)\end{array}$ & $\begin{array}{l}0.0253^{* * *} \\
(0.00271)\end{array}$ & $\begin{array}{l}0.0135^{* * *} \\
(0.00182)\end{array}$ & $\begin{array}{l}0.0165^{* * *} \\
(0.00329)\end{array}$ & $\begin{array}{l}0.0232^{* * *} \\
(0.00258)\end{array}$ \\
\hline Constant & $\begin{array}{c}-58.58^{* * *} \\
(5.310)\end{array}$ & $\begin{array}{c}-50.62^{* * *} \\
(5.438)\end{array}$ & $\begin{array}{c}-26.98^{* * *} \\
(3.650)\end{array}$ & $\begin{array}{c}-32.98^{* * *} \\
(6.611)\end{array}$ & $\begin{array}{c}-46.59^{* * *} \\
(5.172)\end{array}$ \\
\hline Observations & 6302 & 6302 & 6302 & 5060 & 5060 \\
\hline
\end{tabular}

Coefficients from OLS regression with robust SE in parentheses.

${ }^{*} p<.10,{ }^{* *} p<.05,{ }^{* * *} p<.01$ 
Table 9: Effects of Comprehensive Closures on Terrorist Attacks

\begin{tabular}{|c|c|c|c|c|c|}
\hline & $\begin{array}{c}(1) \\
\text { N. Bin. } \\
\text { Attacks }\end{array}$ & $\begin{array}{c}(2) \\
\text { 2SLS } \\
\text { Attacks }\end{array}$ & $\begin{array}{c}(3) \\
\text { 2SLS } \\
\text { Attack 0/1 }\end{array}$ & $\begin{array}{c}(4) \\
\text { N. Bin. } \\
\text { Attacks IP }\end{array}$ & $\begin{array}{c}(5) \\
\text { N. Bin. } \\
\text { Attacks WB }\end{array}$ \\
\hline Closure & $\begin{array}{l}0.442^{* * *} \\
(0.0928)\end{array}$ & $\begin{array}{l}-0.115^{* *} \\
(0.0563)\end{array}$ & $\begin{array}{l}-0.0558 \\
(0.0364)\end{array}$ & & \\
\hline Holiday & $\begin{array}{c}0.194 \\
(0.185)\end{array}$ & & & & \\
\hline Closure x Holiday & $\begin{array}{c}-1.110^{* * *} \\
(0.271)\end{array}$ & & & & \\
\hline Days Since Reopen & & & & $\begin{array}{c}-0.00290^{* * *} \\
(0.000707)\end{array}$ & $\begin{array}{c}0.00117^{*} \\
(0.000669)\end{array}$ \\
\hline Year & $\begin{array}{l}0.0417^{* * *} \\
(0.00730)\end{array}$ & $\begin{array}{c}0.00564^{* * *} \\
(0.00218)\end{array}$ & $\begin{array}{l}0.00233^{*} \\
(0.00137)\end{array}$ & $\begin{array}{l}0.0308^{* * *} \\
(0.00933)\end{array}$ & $\begin{array}{c}0.0959^{* * *} \\
(0.0138)\end{array}$ \\
\hline Constant & $\begin{array}{c}-85.27^{* * *} \\
(14.67)\end{array}$ & $\begin{array}{c}-11.05^{* *} \\
(4.375)\end{array}$ & $\begin{array}{l}-4.503 \\
(2.764)\end{array}$ & $\begin{array}{c}-62.99^{* * *} \\
(18.71)\end{array}$ & $\begin{array}{c}-194.7^{* * *} \\
(27.66)\end{array}$ \\
\hline $\ln ($ alpha $)$ & $\begin{array}{l}0.882^{* * *} \\
(0.0815)\end{array}$ & & & $\begin{array}{c}0.657^{* * *} \\
(0.119)\end{array}$ & $\begin{array}{c}1.198^{* * *} \\
(0.114)\end{array}$ \\
\hline Observations & 6575 & 6575 & 6575 & 5060 & 5060 \\
\hline
\end{tabular}

Robust SE in parentheses.

${ }^{*} p<.10,{ }^{* *} p<.05,{ }^{* * *} p<.01$ 
the probability of attack is greatest immediately after checkpoints reopen, which we explain as terrorists releasing pent-up demand built during closure periods. If strategic behavior, and not the endogenous timing of checkpoint closures, causes this result, then we should observe no relationship between the number of days until a closure and attacks, since presumably the government does not notify terrorists in advance of closing checkpoints. Model 4 fails to find a relationship between the number of days until closure and the probability of a terrorist attack in Israel Proper. 
Table 10: Daily Likelihood of Terror Attacks

\begin{tabular}{|c|c|c|c|c|}
\hline & $\begin{array}{c}(1) \\
\text { N. Bin. } \\
\text { In-Person }\end{array}$ & $\begin{array}{c}(2) \\
\text { N. Bin. } \\
\text { Projectile }\end{array}$ & $\begin{array}{c}(3) \\
\text { 2SLS } \\
\text { Projectile }\end{array}$ & $\begin{array}{c}(4) \\
\text { N. Bin. } \\
\text { Attacks IP }\end{array}$ \\
\hline Closure & $\begin{array}{l}-0.0696 \\
(0.0908)\end{array}$ & $\begin{array}{l}0.299^{* *} \\
(0.148)\end{array}$ & $\begin{array}{c}0.0352 \\
(0.0465)\end{array}$ & \\
\hline Holiday & & $\begin{array}{l}-0.131 \\
(0.273)\end{array}$ & & $\begin{array}{l}-0.229 \\
(0.236)\end{array}$ \\
\hline Closure x Holiday & & $\begin{array}{l}-0.281 \\
(0.340)\end{array}$ & & \\
\hline Days Until Closure & & & & $\begin{array}{c}-0.0000425 \\
(0.000611)\end{array}$ \\
\hline L.Pal. Deaths & $\begin{array}{l}0.206^{* * *} \\
(0.0393)\end{array}$ & $\begin{array}{l}0.638^{* * *} \\
(0.0430)\end{array}$ & $\begin{array}{l}0.247^{* * *} \\
(0.0346)\end{array}$ & $\begin{array}{l}0.615^{* * *} \\
(0.0383)\end{array}$ \\
\hline 2nd Intifada & $\begin{array}{c}1.671^{* * *} \\
(0.154)\end{array}$ & $\begin{array}{c}-1.024^{* * *} \\
(0.168)\end{array}$ & $\begin{array}{c}-0.183^{* * *} \\
(0.0247)\end{array}$ & $\begin{array}{l}-0.159 \\
(0.148)\end{array}$ \\
\hline Right & $\begin{array}{c}0.208^{* *} \\
(0.0817)\end{array}$ & $\begin{array}{c}-0.804^{* * *} \\
(0.102)\end{array}$ & $\begin{array}{c}-0.0963^{* * *} \\
(0.0148)\end{array}$ & $\begin{array}{c}-0.427^{* * *} \\
(0.0870)\end{array}$ \\
\hline Year & $\begin{array}{l}0.132^{* * *} \\
(0.0144)\end{array}$ & $\begin{array}{c}0.0370^{* * *} \\
(0.0141)\end{array}$ & $\begin{array}{c}0.00914^{* * *} \\
(0.00266)\end{array}$ & $\begin{array}{c}0.0426^{* * *} \\
(0.0129)\end{array}$ \\
\hline Constant & $\begin{array}{c}-266.8^{* * *} \\
(28.88)\end{array}$ & $\begin{array}{c}-75.65^{* * *} \\
(28.43)\end{array}$ & $\begin{array}{c}-18.12^{* * *} \\
(5.335)\end{array}$ & $\begin{array}{c}-87.06^{* * *} \\
(25.87)\end{array}$ \\
\hline $\ln$ (alpha) & $\begin{array}{l}0.648^{* * *} \\
(0.0856)\end{array}$ & $\begin{array}{l}0.363^{* *} \\
(0.158)\end{array}$ & & $\begin{array}{l}0.0686 \\
(0.142)\end{array}$ \\
\hline Observations & 6302 & 6302 & 6302 & 5060 \\
\hline
\end{tabular}

Models include season dummies. Robust SE in parentheses.

${ }^{*} p<.10,{ }^{* *} p<.05,{ }^{* * *} p<.01$ 